\title{
LAS EMPRESAS TRANSNACIONALES EN EL ESCENARIO LATINOAMERICANO DEL CAPITALISMO TARDÍO
}

\author{
TRANSNATIONAL CORPORATIONS ON THE LATIN AMERICAN STAGE WITHIN THE \\ FRAMEWORK OF LATE CAPITALISM
}

Marcelo Halperin

\begin{abstract}
RESUMEN
Las transformaciones en la economía global son cada vez más aceleradas y profundas. Este trabajo invita a leerlas y apreciarlas a través del desempeño de sus principales protagonistas: las empresas transnacionales y los Estados nacionales.
\end{abstract}

Los dos tipos de formaciones mantienen entre sí una relación ambivalente: se repelen y confrontan pero a la vez demuestran necesitarse recíprocamente.

Las características del vínculo definen lo que desde J. Habermas se denomina "capitalismo tardío". El motivo central de la tensión entre ambos tipos de formaciones es hoy día el ritmo febril de reproducción del capital y las consiguientes batallas que libran las empresas transnacionales con el objeto de ampliar sus mercados y concentrar la propiedad y el control de los medios de producción para poder realimentar dicho proceso indefinidamente.

Durante la segunda mitad del siglo xx se difundió en América Latina una receta destinada a promover el desarrollo autónomo de distintas subregiones, que según se advirtió estaba comprometido por la acción de las empresas transnacionales. Siguiendo esta receta fueron diseñadas empresas con participación o promoción estatal para competir con las empresas transnacionales. Si bien las iniciativas fracasaron una y otra vez, algunas orientaciones políticas recientes llevan al autor a preguntarse por su viabilidad. En tal sentido, la evolución del sistema global indica que semejantes proyectos políticos resultan de imposible cumplimiento.

¿Cuáles son entonces los motivos que en el capitalismo tardío impiden la creación y gestión de empresas políticamente condicionadas? En primer lugar, las oleadas tecnológicas van sustituyendo productos, servicios, procesos y actividades productivas y de ese modo expulsan de los mercados a las mismas poblaciones que el sistema económico reclama perentoriamente como consumidores y usuarios. Los Estados nacionales -que las fantasías tecnocráticas hasta hoy mismo reputan como entes anacrónicos- reaparecen en la escena internacional, procurando cargar con el costo social interno de esas segregaciones. Así, paradójicamente y hasta donde puedan, deben realimentar al mismo sistema. Es una tarea reparadora que no puede prescindir de las empresas transnacionales, sino que ha de contar con ellas.

En particular, los Estados de países en desarrollo asumen el compromiso de la única forma posible que pueden hacerlo para que se les reconozca previsibilidad: a través de minuciosas regulaciones intergubernamentales, encuadradas bajo los denominados "tratados de libre comercio". Son tratados, usualmente bilaterales, que se van ensamblando y convergiendo laboriosamente. Sus regulaciones, enancadas sobre un soporte multilateral todavía vigente, permiten que los Estados nacionales y las empresas transnacionales acoten sus expectativas mutuas dentro de condiciones de aguda beligerancia económica, lo que sólo puede lograrse mediante una inédita flexibilidad estratégica y operativa de uno y otro lado. 
Revista Aportes para la Integración Latinoamericana Año XXIII, N 36/Junio 2017, ISSN 2468-9912. DNDA: 5318259 en línea

Marcelo Halperin

Las empresas transnacionales en el escenario latinoamericano del capitalismo tardío

Págs. 1-43

Como resultado de su confrontación o cooperación, según sean las cuestiones en juego, dichos actores van modificándose entre sí al interactuar en un entramado de múltiples redes de redes cada vez más complejas e integradas. Son entonces las relaciones mutuas las que están redefiniendo a toda hora a sus respectivas entidades.

¿Se podrá conjeturar sobre el sentido histórico de la tendencia en curso? Por el momento habría que tomar nota de la creciente incertidumbre generada por los efectos adversos del sistema global cuando ya es notoria su propagación territorial en el propio mundo desarrollado. Y adicionalmente aparecen alertas acerca de potenciales eventos climáticos cuya ocurrencia sería incontrolable. En este cuadro la exacerbación de la conectividad parece contraindicada. De ahí el desafío sobreviniente: la reconversión de las organizaciones públicas y privadas para que puedan sustentarse a sí mismas a la hora de interrumpir las conexiones externas, cuando deban recomponerlas y teniendo la idoneidad para funcionar en la transición sin poder contar con ellas.

\section{PALABRAS CLAVE}

Empresas transnacionales, Estados nacionales, capitalismo tardío

\section{ABSTRACT}

Changes in the global economy are increasingly accelerating and deepening. This work invites you to read and appreciate them through the performance of its main protagonists: transnational corporations and national States.

The two types of organizations keep a relationship that is ambivalent: they repel and confront but at the same time they prove to need each other.

The features of the link define what has been called "late capitalism" since J. Habermas. The tension knot between the two types of organizations is today the feverish rate of reproduction of capital and the ensuing battles waged by transnational corporations in order to expand their markets and concentrate ownership and control of the means of production in order to feed the process indefinitely.

During the second half of the twentieth century, a recipe was introduced in Latin America to promote the autonomous development of different sub-regions, which were reported to have been compromised by the actions of transnational corporations. Following this recipe were designed companies with participation or under the state promotion to compete with transnational corporations. While the initiatives failed again and again, some recent policy orientations lead the author to wonder about their viability. In this sense, the evolution of the global system suggests that such political projects are impossible to fulfill.

What about the reasons that prevent the creation and management of companies under political guidelines? At first, technological waves are replacing products, services, processes and productive activities and thus expel from the markets the same populations that the economic system claims peremptorily as consumers and users. National states -which technocratic fantasies even today regard as anachronistic beings-reappear on the international scene, trying to bear the internal social cost of these segregations. Thus, paradoxically and as far as they can, they must feed back to the same system. It is a restorative task that cannot be done without transnational corporations, but must count on them.

In particular, developing country states make a commitment in the only possible way that they can do so in order to be predictable: through detailed inter-governmental regulations, under the socalled "free trade agreements". These treaties, usually bilateral, are joining and converging laboriously. Its regulations, embedded in a multilateral support still in force, allow national states and transnational corporations to meet their mutual expectations under conditions of economic 
Revista Aportes para la Integración Latinoamericana Año XXIII, Nº 36/ Junio 2017, ISSN 2468-9912. DNDA: 5318259 en línea Marcelo Halperin

Las empresas transnacionales en el escenario latinoamericano del capitalismo tardío

Págs. 7 -43

belligerence, which can only be achieved through unprecedented strategic and operational flexibility on both sides.

As a result of their confrontation or cooperation, depending on the issues involved, these actors are changing among themselves as they interact in multiple networks of increasingly complex and integrated systems. It is then mutual relationships that are redefining at all time their respective entities.

Is it possible to conjecture about the historical sense of the current trend? At the moment it should be noted the increasing uncertainty generated by the adverse effects of the global system when its territorial spread in the developed world is already well known. And there are also warnings about potential climatic events whose occurrence would be uncontrollable. In this picture the exacerbation of connectivity seems contraindicated. Hence the overcoming challenge: the reconversion of public and private organizations so that they can support themselves in interrupting external connections, when they have to be rebuilt and having the suitability to operate in the transition even without such connections.

\section{KEY WORDS}

Transnational corporations, national states, late capitalism 
Revista Aportes para la Integración Latinoamericana Año XXIII, N 36/Junio 2017, ISSN 2468-9912. DNDA: 5318259 en línea

Marcelo Halperin

Las empresas transnacionales en el escenario latinoamericano del capitalismo tardío

Págs. 1-43

\section{INTRODUCCIÓN}

Las categorías de "integración económica" por un lado; y las propuestas para una "independencia económica" o "desarrollo autónomo", por otro lado, estuvieron asociadas durante largas décadas en América Latina a través de políticas de integración económica complementadas por formatos empresariales. Estos últimos formatos abarcaron de modo recurrente la creación y promoción de empresas constituidas por el aporte de organismos públicos y fuentes privadas de dos o más países en la región y con el objeto de confrontar con las míticas "empresas transnacionales" (ETN).

La referida línea de pensamiento y acción, con sus distintas versiones, fue jaqueada por dificultades operativas que invalidaron, uno tras otro, los intentos para que estas empresas binacionales o multinacionales pudieran competir con las ETN ${ }^{1}$. Después de múltiples postulaciones, ensayos y fracasos, hoy nos encontramos con que los mercados de la región están internacionalizados a manos de las ETN. Pero más allá de dicho reconocimiento, una y otra vez aparecen sucedáneos de aquellas iniciativas tanto en las agendas de los gobiernos como en el imaginario "progresista" de los claustros. Algunos ejemplos recientes han sido suministrados por la retórica chavista sobre las "empresas grannacionales"2 y por la intervención de las cancillerías del MERCOSUR para presentar la llamada "integración productiva" en derredor de misteriosas "empresas-ancla"3.

\footnotetext{
${ }^{1}$ La bibliografía es muy nutrida debido a la atracción despertada entonces por estas iniciativas, comenzando por el Convenio sobre Industrias Centroamericanas de Integración (1958); los mecanismos del Grupo Andino a partir de la Decisión número 46 de la Comisión del Acuerdo de Cartagena (comentada, entre otros, por Gustavo Fernández: "El régimen de las empresas multinacionales en el Grupo Andino", en revista Derecho de la Integración, INTAL, octubre de 1972, número 11, página 11 y ss.); los programas sectoriales de desarrollo industrial enmarcados por el artículo 38 del Acuerdo de Cartagena en su versión original; así como otras mixturas experimentales como la del acogimiento de la empresa Monómeros Colombo-Venezolanos S.A. al régimen de las empresas multinacionales andinas en 1985.

${ }^{2}$ El primer signo significativo sobre las características de la óptica empresarial de la "Alternativa Bolivariana para los Pueblos de Nuestra América" (ALBA surgió durante la Quinta Cumbre (Barquisimeto, Venezuela, abril de 2007), al firmarse un Acta bajo el título de "Proyecto Grannacional" que incorporó compromisos orientados a la ejecución de emprendimientos en diversas áreas. Entre ellos se destacó la iniciativa para crear una empresa Gran Nacional de Energía, a ser constituida mediante negociaciones entre los mismos Estados. El Consejo de Ministros, creado en aquella Quinta Cumbre, reunido en Caracas el 6 de junio de ese año, acordó de manera genérica la creación de "empresas grannacionales" con participación de los países miembros para que, dentro de sectores estratégicos de sus economías pudieran constituir alternativas frente a las empresas transnacionales. En esta línea, la segunda reunión del Consejo de Ministros, efectuada en La Habana, Cuba, los días 20 y 21 de septiembre de 2007, aprobó
} 
Revista Aportes para la Integración Latinoamericana Año XXIII, N 36/Junio 2017, ISSN 2468-9912. DNDA: 5318259 en línea

nuevos "proyectos grannacionales" (una empresa distribuidora y comercializadora de productos farmacéuticos; el Centro de Vigilancia Epidemiológica; empresas de manejo integral de cuencas; acceso al agua y saneamiento; la Universidad del ALBA, entre otros). Habiéndose llegado a este punto pareció necesario el dictado de un documento de "conceptualización" con directivas para encuadrar los "proyectos grannacionales" y las "empresas grannacionales". El documento, producido por la Sexta Cumbre (Caracas, Venezuela, 24 a 26 de enero de 2008), aclaró que si bien no todo "proyecto grannacional" debía convertirse en una "empresa grannacional", en cambio toda "empresa grannacional" debía ser el producto de un "proyecto grannacional". Tales proyectos fueron concebidos para ser ejecutados entre todos o algunos de los países miembros, en tanto se determinó como requisito esencial de las "empresas grannacionales" que fueran de propiedad absoluta de los Estados aunque con la posibilidad de asociarse con empresas del sector privado a fin de desarrollar determinadas actividades. Acerca de los fundamentos de esta tipología, "el concepto de empresas grannacionales surge en oposición al de las empresas transnacionales, por tanto, su dinámica económica se orientará a privilegiar la producción de bienes y servicios para la satisfacción de las necesidades humanas garantizando su continuidad y rompiendo con la lógica de la reproducción y acumulación del capital (...) La producción final de estas empresas debe destinarse prioritariamente a satisfacer el consumo final o industrial del mercado intra-alba, a objeto de conformar la zona de comercio justo. Sus excedentes podrán colocarse en el mercado internacional (...) Con respecto a la modalidad de estas empresas, (ellas) pueden ser binacionales, con una composición accionaria que garantice la soberanía de cada país. En el caso de las empresas grannacionales entre varios o todos los Estados Miembros, los aportes se harán de acuerdo a las posibilidades de cada Parte. Las decisiones se tomarán siempre por consenso y los márgenes económicos que se obtengan se destinarán al crecimiento de la propia empresa y/o al desarrollo de proyectos de carácter social" (párrafos extraídos del documento "Conceptualización de proyecto y empresa grannacional en el marco del ALBA", emitido en la Sexta Cumbre de Caracas, 26 de enero de 2008).

${ }^{3}$ La vaguedad del concepto "integración productiva" no impidió que un Grupo Ad Hoc creado por Decisión del Consejo Mercado Común (CMC) 52/07 presentara sus propuestas a la LXXII Reunión Ordinaria del Grupo Mercado Común (GMC). Sobre la base de este dictamen se aprobó el Proyecto de Decisión sobre el "Programa de Integración Productiva del MERCOSUR" finalmente adoptado mediante la Decisión CMC 12/2008 en la XXXV Reunión Ordinaria. En sus considerandos, se dice que este Programa "(...) fortalecerá la complementariedad productiva de las empresas del MERCOSUR, principalmente PYMES, y profundizará el proceso de integración del bloque, consolidando el incremento de la competitividad de los sectores productivos de los Estados Partes". El Programa consta de los siguientes apartados: Justificación; Objetivos; Acciones; y el que propone la creación del denominado "Grupo de Integración Productiva del MERCOSUR". Éste último tendrá la misión de presentar al GMC informes periódicos acerca de la marcha del conjunto de las iniciativas enmarcadas por el Programa, así como la de proponer cursos de acción e informar semestralmente al CMC. Entre las justificaciones del Programa, el texto indica que "se debe alentar la complementariedad entre distintos eslabones de la cadena de valor regionales, procurando la efectiva incorporación de producciones de los países de menor tamaño económico relativo en los procesos productivos de todos los socios". Asimismo, "la cooperación intra-industrial sectorial se constituye en un elemento esencial para superar estas fallas de mercado y consolidar la libre circulación de bienes en el espacio ampliado". A propósito de los objetivos, con respecto al sector público la nómina incluye el uso de distintos verbos: promover, facilitar, contribuir, mejorar, estimular, sensibilizar...Las acciones a propulsar desde el sector público son, entre otras: creación de empleo, el desarrollo de redes de proveedores y clientes, consorcios de exportación, clusters, entornos productivos, homogeneización de la producción bajo estándares técnicos, articulación de empresas a través de foros de competitividad, agencias de desarrollo, etc. $Y$ desde el sector privado se esperan, por un lado, asociaciones entre "empresas ancla", caracterizadas por su alto nivel gerencial y de control de calidad con redes de proveedores regionales y de clientes y, por otro lado, la asociación de empresas PYMES de un 
Revista Aportes para la Integración Latinoamericana Año XXIII, N³6/Junio 2017, ISSN 2468-9912. DNDA: 5318259 en línea

Marcelo Halperin

Las empresas transnacionales en el escenario latinoamericano del capitalismo tardío

Págs. 1-43

Es posible que las primeras empresas binacionales o multinacionales y a la vez subregionales hayan fracasado esencialmente por errores en el diseño e implementación. Pero la repetición de esas experiencias hoy día tendría que habérselas con los desafíos de la economía global y la necesidad de los agentes productivos para flexibilizar y diversificar al máximo posible sus estrategias y recursos. En tales condiciones, quizás resulte oportuno preguntarse:

(a) Si tiene sentido insistir con aquella corriente tradicional que procuró sustituir o al menos reducir el papel de las ETN en la región, a través de la creación de empresas binacionales o multinacionales que, por su origen y objeto fueron consideradas como "subregionales" (centroamericanas, andinas, etc.); y

(b) Si ya no tuviera sentido persistir en esos intentos para sustituir o reducir el papel de las ETN, podría justificarse la aplicación de distintas modalidades contractuales y societarias o asociativas entre el sector público y el sector privado para reemplazar ventajosamente aquellas propuestas de confrontación y así dar lugar a una mayor y mejor inserción de las economías latinoamericanas dentro del sistema global.

En todo caso y observando la evolución de dichas vinculaciones público-privado en distintos ámbitos y países, asoman indicios sobre una progresiva transformación tanto en las estructuras de los Estados naciones como de las ETN, dando lugar a que, desde una perspectiva de mediano plazo, se estén formulando prevenciones y conjeturas inquietantes por el carácter aparentemente irreversible de las fragmentaciones observadas.

La próxima sección aborda distintos aspectos de la tan entrañable como conflictiva interacción e interdependencia que anuda a los Estados nacionales y las ETN en esta

mismo sector productivo o de servicios. La batería de acciones previstas incluye: previsión de líneas de cooperación entre organismos, complementación en investigación, desarrollo y transferencia de tecnología, formación de recursos humanos, generación y procesamiento de información, articulación de medidas de facilitación y financiamiento. Al diseñar las modalidades para implementar el Programa, resalta la previsión de un mecanismo con representantes gubernamentales como puntos focales para cada iniciativa y que habrán de interactuar con las áreas de gobierno y sectores productivos en su propio país. Asimismo, cada iniciativa será coordinada técnicamente por uno de los Estados Partes, en el entendimiento que todas ellas tenderán a identificar el interés y viabilizar, en la medida de lo posible, la participación de todos los Estados Partes y, en especial, las economías de menor tamaño relativo. 
Revista Aportes para la Integración Latinoamericana Año XXIII, N 36/Junio 2017, ISSN 2468-9912. DNDA: 5318259 en línea

Marcelo Halperin

Las empresas transnacionales en el escenario latinoamericano del capitalismo tardío

Págs. 1-43

fase de la economía global. Siguen unas breves reflexiones sobre las frustradas iniciativas latinoamericanas para neutralizar a las ETN con políticas-espejo. Más abajo, en las dos secciones finales, se presenta el cuadro de situación que afrontan las organizaciones públicas y privadas en la actualidad a fin de no sucumbir ante las tempestades de su entorno. Finalmente, las conclusiones y conjeturas incluyen una proyección o esbozo del futuro que pone a contraluz algunas imágenes familiares acerca de las conexiones y disrupciones en curso.

\section{Modalidades del entReCRUZAmiento de INTERESES PÚBICOS Y PRIVAdOS EN LA ECONOMÍA GLOBAL}

Es notorio que los Estados nacionales, incluyendo a los Estados de la región, deben extremar hoy día sus instrumentos regulatorios para mantener el control de las actividades desplegadas por las ETN. Debido a su propia índole, por lo demás, las ETN no pueden sino ser reguladas de modo concertado por los Estados donde actúan. Esto explica que las fuentes normativas y los mecanismos para dirimir conflictos entre los Estados y las ETN nos remitan al ordenamiento multilateral (la Organización Mundial del Comercio (OMC) a través de los distintos Acuerdos multilaterales que la conforman $)^{4}$, así

\footnotetext{
${ }^{4}$ Los tiempos de la segunda posguerra estuvieron signados por batallas comerciales para la captura y regulación de los mercados, pero bajo la ley del más fuerte, sin otras mediaciones. Con prácticas extorsivas se impusieron compromisos tales como los destinados a la auto-restricción de exportaciones ("voluntary export restraints") y al establecimiento de límites en el acceso a los mercados ("orderly marketing arrangements"). Las legislaciones internas, tanto de Estados Unidos de América (EUA) como de la Comunidad Europea (CE), convalidaron estas prácticas a través de previsiones que auto-legitimaban la adopción de represalias comerciales (en EUA "U.S. Trade Act Section 301" de 1974 y luego reforzada por un mecanismo de retaliación cruzada, inicialmente a través de la "U.S. Trade Act Section "Super" 301 de 1988; y en la CE "Regulation 2641/84").

Dichas prácticas, encuadradas por la imagen brumosa de una denominada "zona gris", contribuyeron a ordenar las corrientes comerciales y de inversión durante buena parte de la década del setenta (la Ronda Tokio comenzó en 1973 pero sus resultados se formalizaron recién en 1979); y también en la década comprendida por el segundo quinquenio de los ochenta y el primero de los noventa (la Ronda Uruguay se abrió en 1986 y finalizó en 1994). Así, la paz y concertación multilateral pareció llegar recién con la puesta en vigencia de los acuerdos de la OMC en 1995, cuyo significado surge de algunas frases incidentales, como las contenidas en los párrafos 1 y 3 del artículo 11 del Acuerdo sobre Salvaguardias: “...ningún Miembro tratará de adoptar, adoptará ni mantendrá limitaciones voluntarias de las exportaciones, acuerdos de comercialización ordenada $u$ otras medidas similares respecto de las exportaciones o las importaciones (...) Los Miembros no alentarán ni apoyarán la adopción o el mantenimiento, por empresas públicas o privadas, de medidas no gubernamentales equivalentes a las medidas a que se hace referencia...".

Las expectativas se cumplieron en la medida que los acuerdos multilaterales de la OMC, de aplicación obligatoria en todos los Estados Miembros, enmarcaron desde entonces todas las
} 
Revista Aportes para la Integración Latinoamericana Año XXIII, N 36/Junio 2017, ISSN 2468-9912. DNDA: 5318259 en línea

Marcelo Halperin

Las empresas transnacionales en el escenario latinoamericano del capitalismo tardío

Págs. 1-43

como a los tratados "de libre comercio" (TLC) y esquemas compromisorios afines y complementarios ${ }^{5}$.

Entre los problemas a encarar en la materia y cuyos principales afectados son los países en desarrollo, resaltan:

a) Las cuestiones relativas a elusión o evasión por las ETN, de los procedimientos para el control aduanero de valoración de mercaderías y el consiguiente pago de gravámenes con motivo del comercio intra-firma (precios de transferencia).

El régimen multilateral prevé, como un caso especial para determinar la valoración aduanera de las mercaderías, el de las empresas "vinculadas". De todos modos y como se ha demostrado fehacientemente desde su sanción, los procedimientos previstos son de baja confiabilidad por tres motivos esenciales:

(i) La minuciosidad metodológica del Acuerdo para determinar ese valor aún en el caso de las empresas vinculadas, no contempla la hipótesis de una ETN ostentando posición dominante y que, como tal, genere una distorsión de los precios condicionando así los que puedan fijarse en distintas transacciones. Con estos otros "precios" son los que

políticas comerciales y otras políticas relativas a procedimientos, protección sanitaria, reglamentos técnicos, propiedad intelectual e inversiones vinculadas al comercio. $Y$ el remozamiento del Sistema de Solución de Diferencias a través de una secuencia de mecanismos de coerción progresiva, reforzó el imaginario colectivo acerca de la existencia de una especie de "comunidad" económica internacional.

${ }^{5}$ Hace algún tiempo este autor se permitió asignar al capitalismo tardío la carencia de una "racionalidad global", idea relacionada con dos cuestiones: (i) la notoria incapacidad estructural para reabsorber los efectos indeseables del desempeño del sistema (esto es, los desechos humanos y materiales generados por la aceleración del ciclo de producto y las sustituciones tecnológicas); y en relación con lo anterior (ii) la extrema dificultad para sostener una cosmovisión compartida de ideales de coexistencia. En este marco, el auge de un bilateralismo económico de tipo transaccional como el de los denominados "tratados de libre comercio" (TLC) parece afín a las necesidades de subsistencia de las sociedades nacionales dentro de la economía global, frente a las amenazas derivadas de una expansión devoradora de mercados y la simultánea concentración de factores y recursos para la acumulación reproductiva (o apropiación del excedente generado por los cambios tecnológicos, siguiendo a Prebisch). Pesa sobre los Estados nacionales la necesidad de intervenir en su papel de protectores sociales ante los mencionados efectos adversos de la economía global (en tal sentido véase, del autor: "Las relaciones económicas internacionales y los países en desarrollo: el recurso a una racionalidad acotada", en revista Aportes para la Integración Latinoamericana número 22, junio 2010). Desde el punto de vista estrictamente normativo, el predominio de los TLC como fuente de derecho a expensas de la OMC suele simplificarse por dos siglas: "OMC +" y "OMC X", para expresar en el primer caso la insuficiencia y en el segundo la carencia normativa multilateral frente a los desafíos cada vez más acuciantes de la economía global. 
Revista Aportes para la Integración Latinoamericana Año XXIII, N 36/ Junio 2017, ISSN 2468-9912. DNDA: 5318259 en línea

Marcelo Halperin

Las empresas transnacionales en el escenario latinoamericano del capitalismo tardío

Págs. 1-43

precisamente-según el Acuerdo- deben compararse los precios declarados para que la autoridad pueda establecer la valoración final ${ }^{6}$;

(ii) Al determinar el carácter de "vinculación" entre las empresas exportadora e importadora, el Acuerdo fija criterios de propiedad, control y dirección societarias, aceptando además la figura de una "asociación en negocios" pero sólo cuando dicha asociación esté "legalmente reconocida", excluyendo así otras situaciones de vinculación informal $u$ ocasional pero que son cada vez más frecuentes por los procesos de fragmentación y recomposición de las organizaciones en el fragor de la economía global ${ }^{7}$; y

(iii) A todo evento, los Estados latinoamericanos no suelen estar en condiciones de llevar a cabo investigaciones administrativas con la precisión y celeridad suficiente como para desalentar estas infracciones aduaneras. En especial los seis métodos de valoración admitidos por el Acuerdo, en sustitución del valor declarado de transacción cuando éste no resulte verosímil, deben ser considerados, uno después de otro según el orden estricto indicado en el Acuerdo y con notificaciones exhaustivas a los interesados ${ }^{8}$.

\footnotetext{
${ }^{6}$ Las ETN frecuentemente están en condiciones de acaparar o manipular mercados valiéndose de las operaciones comerciales entre sus distintos asientos geográficos imputando precios ("de transferencia") que pueden responder a facturaciones contables ficticias. $Y$ el volumen del comercio intra-firma dentro del total de las transacciones internacionales es en la actualidad de tal envergadura, que la metodología establecida por el Acuerdo sobre valoración aduanera ("Acuerdo Relativo a la Aplicación del Artículo VII del Acuerdo General sobre Aranceles Aduaneros y Comercio de 1994") resulta insuficiente por su imprecisión, más allá de una aparente minuciosidad. Basta observar que las regulaciones del Acuerdo no asocian el comercio internacional entre empresas vinculadas con la hipótesis de posición dominante en los mercados, porque si lo hicieran no podrían fijar una metodología que, para establecer el valor en aduana recurre a la comparación de precios en transacciones efectuadas por terceros. Es cierto que en última instancia se prevé la posibilidad de fijar el valor en aduana según "criterios razonables" (Acuerdo citado, artículo 7), pero aquí afloran las dificultades operativas de los organismos públicos tributarios de los países en desarrollo, como se advierte más adelante.

${ }^{7}$ El artículo 15, párrafo 4 del Acuerdo sobre valoración aduanera, contiene la enumeración taxativa de casos considerados como vinculantes entre personas (físicas y jurídicas) a los efectos de dicho Acuerdo.

${ }^{8}$ La Organización para la Cooperación y el Desarrollo Económico (OCDE) publicó en julio de 2010 sus "Directrices aplicables en materia de precios de transferencia a empresas multinacionales y administraciones tributarias", contemplando la suscripción de acuerdos empresa-administración tributaria del Estado de importación, con el objeto de convenir criterios a ser implementados durante un período predeterminado y para un conjunto de operaciones comerciales de exportaciónimportación entre empresas vinculadas. El objeto de este mecanismo ("advance pricing arrangements", APA) es el de sortear por anticipado posibles controversias administrativas y
} 
Revista Aportes para la Integración Latinoamericana Año XXIII, N 36/ Junio 2017, ISSN 2468-9912. DNDA: 5318259 en línea

Marcelo Halperin

Las empresas transnacionales en el escenario latinoamericano del capitalismo tardío

Págs. 1-43

b) Los entuertos generados con motivo de la elusión o evasión de las regulaciones destinadas a neutralizar el dumping.

La inclusión del artículo VI en el GATT (1947) puso en evidencia que, más allá de las invocaciones al libre comercio, los consensos logrados en la segunda posguerra incorporaron una dosis de protección a las actividades económicas asentadas en los mercados internos a título de "lealtad" comercial. Desde entonces, puede hacerse un seguimiento de la puja entre las ETN (en sus afanes predatorios puestos en la actividad exportadora) y los Estados nacionales en tanto importadores como garantes de las inversiones asentadas dentro de sus propios territorios aduaneros. La tensión entre ambas fuentes de poder económico aparece racionalizada por dos vías: las reglamentaciones multilaterales ("códigos") para la adopción de medidas antidumping que se fueron sucediendo desde la Ronda Kennedy ${ }^{9}$; y los debates académicos acerca de la consistencia teórica de las políticas antidumping, bajo el influjo de las corrientes neoclásicas. A la búsqueda de una especie de transacción, el "código" sancionado en la Ronda Uruguay pero ahora con carácter obligatorio para todos los Estados Miembros de la OMC intentó dotar a los procedimientos administrativos internos de la mayor transparencia y equidad posibles ${ }^{10}$. Desde entonces, el proceso de expansión de la

judiciales. Pero la determinación de precios de transferencia sobre la base de una concertación previa relativa a la aplicación de criterios de comparación, requiere una preparación técnica que difícilmente pueden alcanzar los organismos públicos de países en desarrollo, incluyendo a los latinoamericanos.

${ }^{9}$ El primero de los códigos antidumping surgió de la Ronda Kennedy (1964-1967); luego rigió el acordado al cabo de la Ronda Tokio (1973-1979); hasta que finalmente fue sancionado el texto en vigor como resultado de la Ronda Uruguay (1986-1994), con carácter obligatorio para todos los Estados Miembros de la OMC.

${ }^{10}$ El Acuerdo Relativo a la Aplicación del Artículo VI del Acuerdo General sobre Aranceles Aduaneros y Comercio de 1994, corrigió en varios puntos a las disciplinas establecidas en el "código" de la Ronda Tokio para el uso de medidas antidumping en los Estados importadores afectados por maniobras desleales. El primer punto, altamente significativo, es el del estatuto de obligatoriedad con respecto a los acuerdos multilaterales para todos los Estados Miembros de la OMC, que hasta entonces habían sido de adopción voluntaria. Por lo demás, el Acuerdo antidumping introdujo cambios relevantes en su normativa respecto del que había estado vigente desde la Ronda Tokio (entre los Estados que lo habían adoptado, básicamente países desarrollados). Las modificaciones introducidas incluyeron: una condición de representatividad mínima obligatoria requerida a los productores nacionales a fin de reconocerles legitimación procesal ante las autoridades nacionales de aplicación; obligación impuesta a la autoridad nacional de aplicación de notificar al gobierno del país exportador interesado con anterioridad a la apertura de la investigación administrativa; derecho a la intervención en el procedimiento administrativo interno que le es reconocido a los adquirentes locales de los productos sobre los cuales recae la investigación; derecho a la intervención en el procedimiento administrativo interno reconocido a 
Revista Aportes para la Integración Latinoamericana Año XXIII, N³6/Junio 2017, ISSN 2468-9912. DNDA: 5318259 en línea

Marcelo Halperin

Las empresas transnacionales en el escenario latinoamericano del capitalismo tardío

Págs. 1-43

economía global se va reflejando en una progresiva reducción del recurso defensivo: las ETN parecen estar ganando la batalla ${ }^{11}$.

Por último, si bien en la puja entre los Estados nacionales y las ETN, estas últimas fueron las principales afectadas por las medidas de protección anti-dumping, en algunos casos ha ocurrido lo contrario: resultaron beneficiarias directas de esas mismas medidas de protección al influenciar a gobiernos de países donde asentaron subsidiarias o filiales con el objeto de preservar un mercado intemo cautivo. Éste último es el caso del Brasil ${ }^{12}$.

c) Los requerimientos efectuados por las ETN durante la negociación o renegociación y el consecuente aprovechamiento de las concesiones y beneficios concertados entre distintos Estados a través de los TLC con especial referencia al desarrollo del intercambio de bienes intermedios.

El crecimiento exponencial del formato "TLC" debe asociarse, precisamente, a esta modalidad adoptada por las ETN a fin de procurar una expansión comercial y la simultánea concentración de factores y recursos para su acumulación reproductiva. En tal sentido, los TLC constituyen el mecanismo que, superpuesto a las disciplinas multilaterales, viabiliza dichas estrategias corporativas en la medida que ofrece mayor previsibilidad y certeza en la determinación de las concesiones y ventajas. El aumento del número de TLC negociados en los últimos años se debe a esta cualidad pero también a su coincidencia con los objetivos de los Estados nacionales, que deben contraer dichos compromisos para regular y eventualmente reducir los efectos adversos de la economía global sobre sus residentes. Esta ganancia inicial de previsibilidad y certeza consiste en que:

consumidores de los mismos productos; y plazo mínimo y obligatorio de espera que debe cumplir la autoridad nacional de aplicación antes de dictar medidas provisionales.

${ }^{11}$ Los gobiernos de países como Canadá, Australia y Nueva Zelandia recurrían asiduamente a los procedimientos antidumping durante las décadas de los ochenta y los noventa, pero luego fueron disminuyendo esas intervenciones. Y también decrecieron tanto en Estados Unidos de América como en la UNIÓN EUROPEA, que habían sido los principales usuarios de las reglamentaciones antidumping. Véase, en tal sentido, las estadísticas de la OMC y el documento de José Tavares de Araujo Jr.: "Anatomía de protección antidumping en Brasil", Textos CINDES número 45, marzo de 2017, Río de Janeiro, Brasil (en portugués).

${ }^{12}$ José Tavares de Araujo Jr.: "Anatomía de protección antidumping en Brasil" citado. 
Revista Aportes para la Integración Latinoamericana Año XXIII, N³6/Junio 2017, ISSN 2468-9912. DNDA: 5318259 en línea

Marcelo Halperin

Las empresas transnacionales en el escenario latinoamericano del capitalismo tardío

Págs. 1 -43

(i) EI TLC constituye un compromiso intergubernamental sustentado estrictamente por el criterio de reciprocidad, respaldado en el orden multilateral pero cuyas concesiones, beneficios y ventajas son el resultado de negociaciones entre las Partes;

(ii) El TLC reúne en un solo corpus normativo a todas las disciplinas directamente involucradas en el comercio, incluyendo al de bienes intermedios (regímenes arancelario y no arancelario; calificaciones específicas de origen; comercio de servicios; inversiones directas); y

(iii) Proporciona el marco para su implementación (al instituir comités intergubernamentales asignados al tratamiento de cada una de las materias negociadas).

Entre las regulaciones de política comercial dispuestas por los TLC, resultan particularmente sensibles las afinidades y correspondencias entre los programas de desgravación, los procedimientos aduaneros, las medidas no arancelarias y los requisitos específicos de origen, atendiendo a que, precisamente, a los efectos del comercio de bienes intermedios es esencial compatibilizar los niveles de protección arancelaria, los procedimientos aduaneros, las medidas no arancelarias para el ingreso de materias primas e insumos y la calificación específica de origen. Correlacionando estos aspectos, un analista puede inferir cuál es la orientación sobre política productiva interna del país huésped de las ETN bajo los TLC que haya concertado.

Asimismo, se trate o no del comercio de bienes intermedios y sus implicaciones en la explotación de cadenas de valor, es sabido que las condiciones para el asentamiento de filiales tienen un peso decisivo en las estrategias de las ETN. Además de las seguridades de integridad patrimonial que pueden obtener a través de los tratados internacionales de protección y promoción de inversiones, resulta esencial que el Estado Parte donde se asienta el inversionista (que suele ser la filial o subsidiaria de una ETN), le reconozca: (i) el derecho a recurrir ante un tribunal arbitral internacional en caso de controversia con dicho Estado anfitrión ${ }^{13}$; y (ii) a su contra-Parte (que suele ser el país donde se asienta la

${ }^{13}$ Como instancia arbitral para dirimir controversias entre los inversionistas extranjeros y los Estados de radicación de dichas inversiones, resalta el papel del "Centro Internacional de Arreglo de Diferencias Relativas a Inversiones" (CIADI), previsto por numerosos Tratados de Promoción y Protección Recíproca de Inversiones. Es una institución creada a instancias del Banco Mundial por 
Revista Aportes para la Integración Latinoamericana Año XXIII, N 36/Junio 2017, ISSN 2468-9912. DNDA: 5318259 en línea

Marcelo Halperin

Las empresas transnacionales en el escenario latinoamericano del capitalismo tardío

Págs. 1-43

matriz de la ETN), la facultad de subrogarse en los derechos del inversionista con motivo de aquella controversia. Un signo llamativo sobre el avance de las ETN en desmedro de las políticas internas de los países que hospedan a filiales y subsidiarias, ha sido la pretensión, a veces lograda en las instancias arbitrales, de recibir reparaciones por haberse discontinuado las políticas macroeconómicas establecidas al momento de su radicación. Sin embargo, esta tendencia parece estar revirtiéndose $e^{14}$.

Es muy frecuente que los tratados internacionales de promoción y protección de inversiones se incorporen a los TLC.

d) La adopción e imposición por las ETN de estándares ("normas") de inocuidad, calidad, seguridad o protección ambiental que, aunque carezcan de respaldo jurídico estatal o interestatal, en la práctica condicionan el acceso a los mercados donde son aplicados.

la Convención de Washington de 1965. No cuenta con tribunal permanente sino que, ante cada caso el CIADI constituye un tribunal arbitral.

${ }^{14}$ Sobre la base de cláusulas especialmente contempladas en los Tratados de Promoción y Protección Recíproca de Inversiones, pero más frecuentemente por el pronunciamiento de los árbitros ante reclamos de las ETN, se había difundido en los últimos años la tendencia a cuestionar políticas económicas llevadas a cabo por Estados anfitriones, cuando afectaran las condiciones que habían ponderado los inversionistas al decidir su asentamiento en ese territorio. De ahí que comenzaran a utilizarse las denominadas "cláusulas de excepción", destinadas a eximir a los Estados de responsabilidad, frente a los inversionistas extranjeros radicados bajo su jurisdicción, por la adopción ulterior de políticas económicas aunque pudieran alterar las condiciones del mercado interno. El texto de dichas cláusulas replica contenidos del ordenamiento multilateral de la OMC, expuestos en el artículo XX del GATT (para el comercio de bienes) y en el artículo XIV del GATS (para el comercio de servicios). En general, "(...) comparten tres elementos: 1. Una lista exhaustiva de objetivos de políticas permisibles: por ejemplo, la protección de la vida o la salud humana, animal o vegetal, o la conservación de los recursos naturales; 2. Un (...) nexo, denotando el vínculo entre una medida estatal y un objetivo permisible, (tales como) "necesario para", "relativo a" y "diseñado y aplicado para"; y 3. Una prohibición arbitraria" (Sabanogullari, Levent: "Los méritos y limitaciones de las cláusulas de excepción en la práctica contemporánea de los tratados de inversión", publicado en el boletín "Investment Treaty News" del Instituto Internacional de Derecho Sustentable" número 2, tomo 6, mayo 2015). El autor citado advierte que, a tenor de los sucesivos informes de la UNCTAD, $(2013 ; 2014)$ va aumentando el número de Tratados que incorporan este tipo de excepciones, si bien todavía integran una pequeña minoría respecto de los más de tres mil Tratados celebrados en la materia. Pero cabría una reflexión adicional con respecto al significado de la inserción de semejantes cláusulas con respecto a la porfía entre los Estados nacionales y las ETN. La pretensión de éstas últimas para interferir formalmente en las políticas internas de los países donde radican filiales o subsidiarias es relativamente novedosa y, en cualquier caso, el intento de amortiguar su impacto a través de la concertación de las cláusulas de excepción, en principio confirma el reconocimiento, por los Estados nacionales, de esa misma pretensión. 
Revista Aportes para la Integración Latinoamericana Año XXIII, N³6/Junio 2017, ISSN 2468-9912. DNDA: 5318259 en línea

Marcelo Halperin

Las empresas transnacionales en el escenario latinoamericano del capitalismo tardío

Págs. 1-43

Estos estándares constituyen una restricción que obstaculiza el acceso a dichos mercados por bienes o servicios originarios de países cuyas empresas, especialmente las pequeñas y medianas, no suelen estar en condiciones de cumplir con ellos ${ }^{15}$.

Después de largos años de escarceos intergubernamentales en los Comités que administran los Acuerdos de la OMC relativos a medidas sanitarias y fitosanitarias y sobre reglamentos y normas técnicas, ha quedado en evidencia la imposibilidad de controlar las "normas privadas" que fijan reglas para certificaciones y sellados en beneficio, directo o indirecto, de las ETN. Un indicador normativo sobre el deterioro del orden multilateral es el de la creciente inutilidad de las disciplinas en materia de medidas sanitarias y fitosanitarias y de obstáculos técnicos al comercio en el marco de los respectivos ordenamientos de la OMC, frente a las exigencias adicionales sobre inocuidad alimentaria y solicitud de certificaciones técnicas a las que se atienen corporaciones privadas residentes en países desarrollados cuando comercializan o importan productos de distinta especie.

Si bien el artículo 13 del Acuerdo sobre Medidas Sanitarias y Fitosanitarias atribuye a los Estados Miembros plena responsabilidad para la observancia de todas las obligaciones estipuladas en el mismo, difícilmente podría suponerse la procedencia de reclamaciones frente a decisiones enteramente privadas (y por lo tanto encuadradas dentro de la libertad de comercio) por las cuales determinadas empresas fijan requisitos de inocuidad y calidad que exceden los criterios objetivos de legitimidad negociados multilateralmente. De esa manera las empresas radicadas en países desarrollados prefieren importar o bien adquirir en el mercado interno mercaderías dotadas de certificaciones que van más allá de los límites mínimos de tolerancia convenidos multilateralmente (OMC+). En tal sentido, es cierto que los requerimientos de importadores o compradores radicados en países desarrollados pueden ser legítimamente interpretados como un exceso de celo para la protección de la vida, la salud o la seguridad de los consumidores, al exigir certificaciones

\footnotetext{
15 "Many studies have noted that the main problem with private standards is the relatively high cost of certification required, which is particularly burdensome for small producers and there are many more small producers in developing countries. Another concern is that many private standards tend to require the use of specific processing and testing techniques that are based on state-of-the-art technologies not available (or too costly) for small producers" (texto extraído del documento de Bernard Vallat "Considerations relevant to private standards in the fields of animal health, food safety and animal welfare" editado por la OMC el 25 de febrero de 2008 y catalogado G/SPS/GEN/822).
} 
Revista Aportes para la Integración Latinoamericana Año XXIII, N 36/Junio 2017, ISSN 2468-9912. DNDA: 5318259 en línea

Marcelo Halperin

Las empresas transnacionales en el escenario latinoamericano del capitalismo tardío

Págs. 1-43

sobreabundantes como condición para adquirir determinados productos. $\mathrm{Y}$ tales requerimientos pueden ser también legítimamente interpretados como un obstáculo a la competencia comercial libre y leal. Pero si al hacerlo no vulneran el principio de trato nacional y por ende se solicitan los mismos estándares a proveedores locales y a extranjeros, ¿a qué título deberían responder por ello los Estados Miembros de la OMC donde esas empresas estén radicadas? ${ }^{16}$

En el marco de los TLC tampoco se han registrado avances sustanciales tales como la formalización de códigos "de buena conducta" o la sanción de reglas de transparencia para desalentar estas prácticas que, por el contrario, se van generalizando.

e) La tendencia al acaparamiento de mercados a través de tecnologías cuya utilización supone la necesidad de superar los límites tradicionales impuestos por las disposiciones que regulan la competencia comercial. Cuando se trata de áreas vinculadas a la prestación de servicios públicos esenciales (energía, telecomunicaciones), los Estados donde se radican matrices, filiales o subsidiarias de ETN tienden a reconocerles la legitimidad del exceso, hasta un punto que suele denominarse "abuso de posición dominante" en lugar de sancionarse lisa y llanamente a la "posición dominante"17.

\footnotetext{
${ }^{16}$ Esta impotencia política para encauzar la lealtad comercial ha sido reflejada por la inoperancia tanto del Comité de Medidas Sanitarias y Fitosanitarias (MSF) como por el Comité del Acuerdo de Obstáculos Técnicos al Comercio (OTC). En éste último aún no ha habido pronunciamientos sobre los estándares privados. En cambio, el Comité MSF, en 2008 y a iniciativa de un grupo de Miembros, convocó a un grupo de trabajo ad hoc para que dictaminara sobre normas privadas relacionadas con cuestiones sanitarias y fitosanitarias. Contando con su dictamen final (documento G/SPS/W/256), el Comité adoptó una Decisión que consta de cinco medidas a través de las cuales se limita a: promover circuitos de información del propio Comité con el CODEX, la Organización Mundial de Sanidad Animal (OIE) y la Convención Internacional de Protección Fitosanitaria (CIPF); disponer la obtención de informaciones adicionales sobre normas privadas acudiendo a través de la Secretaria a otros foros de la OMC; e instar a los Miembros de la OMC a "sensibilizar" a las instituciones emisoras de normas privadas con respecto a las disposiciones multilaterales vigentes (documento G/SPS/55 fechado el 6 de abril de 2011). Si esta disposición parece inoperante, no han de ser mejores las expectativas para controlar las normas privadas aplicadas sobre productos manufacturados, dado que el Comité del Acuerdo OTC ni siquiera ha llegado a expedirse.

${ }_{17}$ La Declaración Ministerial de Doha (14 de noviembre de 2001) al abrir la ronda que hipotéticamente todavía hoy continúa funcionando, previó la celebración de negociaciones alusivas a la defensa de la competencia para después del quinto período de sesiones de la Conferencia Ministerial. Dichas negociaciones debían guiarse por una Decisión que iba a suministrar la definición de las modalidades (numeral 23 de la Declaración de Doha). Entretanto, un Grupo de Trabajo tenía la misión de avanzar en temas específicos (transparencia; no discriminación; equidad
} 
Revista Aportes para la Integración Latinoamericana Año XXIII, N 36/Junio 2017, ISSN 2468-9912. DNDA: 5318259 en línea

Marcelo Halperin

Las empresas transnacionales en el escenario latinoamericano del capitalismo tardío

Págs. 1-43

Este nivel de resignación política para garantizar condiciones de competencia distintas a las exigidas en otras actividades, se justifica por la necesidad de suministrar a poblaciones extendidas una variedad de servicios considerados imprescindibles y cuya infraestructura requiere financiamiento imposible de sostener con los cuadros tarifarios.

La legitimidad asignada a posiciones dominantes para la provisión de servicios energéticos y de telecomunicaciones es especialmente notoria en países en desarrollo, lo que se advierte tanto por su legislación interna como también por los compromisos asumidos en los $\mathrm{TLC}^{18}$. Sin embargo, frente al aumento de la incertidumbre global se

procesal; disposiciones sobre cárteles intrínsecamente nocivos (numeral 25 de la Declaración citada). De aquellas pretensiones quedaron en pie únicamente las buenas intenciones. En particular, a propósito del sector de telecomunicaciones básicas, en febrero de 1997 habían finalizado las negociaciones que permitieron incorporar un cuarto protocolo anexo al Acuerdo General sobre el Comercio de Servicios (Acuerdo individualizado por las siglas "AGCS" en español y "GATS" en inglés). Si bien participaron todos los países desarrollados y numerosos países de América Latina y el Caribe, las ofertas allí consagradas fueron rápidamente horadadas por la imprecisión o vaguedad originaria de los conceptos empleados y que las innovaciones tecnológicas sobrevinientes en muchos casos los convirtieron en anacrónicos. Por lo demás, resulta muy difícil multilateralizar concesiones sobre una materia en la cual el monopolio, predominio u acaparamiento de los mercados internos por empresas privadas parece indispensable para el suministro de las prestaciones. Al respecto, acerca de la intención política de fijar un límite de tolerancia a dichas posiciones monopólicas o dominantes abundan los ejemplos en la UNIÓN EUROPEA sobre la necesidad de recurrir a "guías" o ejemplos (así, "Guidelines on the application of EEC competition rules in the telecommunications sector", documento del año 1991 catalogado como 199/C233/02). Un difundido texto de orientación general sobre la normativa comunitaria de entonces, titulado "Notice on the application of the competition rules to access agreements in the telecommunications sector: Framework, Relevant and Principles", publicado el 22 de agosto de 1998 en el diario oficial de las Comunidades Europeas (catalogado como 98/C 265/02) reconocía que: "(...) 14. Community competition rules are not sufficient to remedy all the various problems in the telecommunications sector (...)".

${ }^{18}$ En los TLC celebrados por países latinoamericanos entre sí y con terceros países, son muy frecuentemente incorporadas dentro del capítulo sobre servicios públicos de telecomunicaciones, distintas obligaciones específicamente destinadas a proveedores "monopólicos", "dominantes" o "importantes". Debe tenerse en cuenta que aquí "dominante" o "importante" suelen utilizarse como adjetivos equivalentes. EI TLC MÉXICO-PANAMÁ reconoce dicha sinonimia y define difusamente que: "proveedor dominante o importante (...) (es aquel) que tiene la capacidad de afectar de manera importante las condiciones de participación, desde el punto de vista de los precios y del suministro en el mercado relevante de redes o servicios públicos de telecomunicaciones, como resultado de: (a) el control de los elementos esenciales, o (b) el uso de su posición en el mercado" (artículo 12.1). En este marco, las medidas que se reservan las Partes en el marco de los TLC a fin de contrarrestar las prácticas abusivas son usualmente denominadas "salvaguardias competitivas". Entre los TLC con las características indicadas, pueden mencionarse: CAFTA DR. (artículo 13.4); CENTROAMÉRICA-PANAMÁ (artículos 13.02 y 13.07); CENTROAMÉRICA-UE (artículo 188); CENTROAMÉRICA-CHILE (artículo 13.07); CENTROAMÉRICA-MÉXICO (artículo 13.5); COLOMBIA-MÉXICO (artículo 11.07); COLOMBIA-EUA (artículo 14.4); CHILE-EUA (artículo 13.4); CHILE-COREA DEL SUR (artículo 12.6); CHILE-MÉXICO (artículo 12.06); CHILE-AUSTRALIA (capítulo 11 sección C); MÉXICO-PANAMÁ (artículo 12.5); MÉXICO-URUGUAY (artículo 11.06); 
Revista Aportes para la Integración Latinoamericana Año XXIII, N 36/ Junio 2017, ISSN 2468-9912. DNDA: 5318259 en línea

Marcelo Halperin

Las empresas transnacionales en el escenario latinoamericano del capitalismo tardío

Págs. 1-43

avizora una necesidad creciente para compatibilizar la conectividad con la de garantizar la preservación de servicios esenciales ante contingencias externas (eventos no controlables desde cada país individualmente). De tal modo, ya no habría tanto margen para la pasividad estatal frente a las ETN proveedoras de dichos servicios públicos. En principio, se observa una tendencia a la complementación de los sistemas que suministran energías derivadas de la combustión de residuos fósiles por el incipiente desarrollo de tecnologías "limpias" que, en general, son susceptibles de mayor descentralización de sus fuentes y circuitos y por lo tanto más accesibles al control estatal de las empresas proveedoras ${ }^{19}$.

f) La participación en actividades conjuntas de organismos públicos, empresas estatales o para-estatales con ETN hasta el punto de diluir el límite (que la teoría jurídica supuestamente había resuelto) entre lo público y lo privado.

Es decir que aparecen engendros asociativos, societarios o contractuales mediante los cuales se genera una interacción público-privado que llega a resultar inmanejable para determinar tanto los órdenes de competencia propiamente estatales como las

NAFTA (artículo 1305); PANAMÁ-EUA (artículo 13.4); PERÚ-EUA (artículo 14.4); PERÚ-JAPÓN (artículo 120); PERÚ-CANADÁ (artículo 1003).

${ }^{19}$ Las fuentes renovables de energía se caracterizan por su adecuación a sistemas de suministro directo a los consumidores o bien a través de redes locales, según los casos. La energía solar fotovoltaica, por ejemplo, en distintos países ya da lugar a contratos entre particulares que la generan y empresas distribuidoras, casi siempre organismos estatales o concesionarias de servicios públicos, que intervienen comprándola para luego inyectarla en redes de consumidores. Asimismo, la intervención del Estado resulta indispensable cuando se trata de asociar la provisión de energía con el saneamiento urbano y periurbano, a través del tratamiento de la biomasa, es decir, la instalación o la promoción de plantas que procesan efluentes industriales, agroindustriales y domésticos, generándose biogás o fertilizantes. Menor atención prestan los gobiernos de países en desarrollo a los emprendimientos a través de los cuales precisamente se puede proporcionar recursos energéticos a poblaciones sistemática u ocasionalmente aisladas: hornos solares portátiles (logrados por la argentina Victoria Riqué); lámparas alimentadas con baterías que a través de electrodos pueden capturar electrones en el mismo terreno (creación de la Universidad de Ingeniería y Tecnología del Perú); heladeras a base de arcilla (Go Energyless en Marruecos)...Y finalmente se destaca, como un indicador más del anacronismo normativo multilateral, la falta de un régimen que reconozca la legitimidad de las subvenciones estatales -al menos, las de países en desarrollo- con el fin de promover el desarrollo de las energías renovables. Esta carencia es todavía más llamativa si la confrontamos con las iniciativas tendientes a reducir la emisión de gases de efecto invernadero y que se hacen notar, por ejemplo, cuando los países desarrollados pretenden desgravar progresivamente las transacciones internacionales de productos y servicios "ambientales". En tal sentido, véanse las dificultades para elaborar una jurisprudencia consistente sobre dichas subvenciones, dentro del Sistema de Solución de Diferencias de la OMC (Wei Zhuang: "Hacia un acuerdo comercial para regular los incentivos a las energías renovables", en revista Puentes volumen 17 número 6, septiembre 2016, página 24 y ss.). 
Revista Aportes para la Integración Latinoamericana Año XXIII, N 36/Junio 2017, ISSN 2468-9912. DNDA: 5318259 en línea

Marcelo Halperin

Las empresas transnacionales en el escenario latinoamericano del capitalismo tardío

Págs. 1-43

responsabilidades privadas. En tales circunstancias, deslindar "lo público" de "lo privado" se hace particularmente difícil a la hora de ponderar las ayudas o subvenciones estatales a conglomerados empresariales que tienen composición híbrida o que actúan bajo un régimen equívoco. ¿Cuándo se justifican los derechos compensatorios aplicados por los Estados miembros de la OMC contra las subvenciones otorgadas por otros Estados miembros a empresas o entidades inmersas en aquellas composiciones híbridas o bajo un régimen equívoco ${ }^{20}$

Esta interacción deja huellas indelebles en sus protagonistas: proclividad a la fragmentación y reconfiguración tanto de las ETN como de las mismas estructuras estatales que comparten los emprendimientos. La sociología de las organizaciones está cada vez más atenta a los procesos de fractura y reconfiguración estructural de las empresas a partir del impacto producido en ellas por eventos o situaciones imprevistas en su entorno. En el caso de las organizaciones públicas ya han sido advertidos desmembramientos internos con motivo de la interacción sistemática de algunos departamentos o sectores de una organización pública compleja con empresas o agentes privados $^{21}$.

\footnotetext{
${ }^{20}$ Un caso memorable por su complejidad fue el planteado dentro del Sistema de Solución de Diferencias por la UNIÓN EUROPEA contra ESTADOS UNIDOS DE AMÉRICA por las subvenciones para investigación y desarrollo aeronáutico en beneficio de la empresa Boeing y que parecían perjudicar a la empresa Airbus a través, entre otras cosas, de los efectos en la provisión de tecnología. El órgano de Apelaciones pudo constatar, entre otras cosas, que la Administración Nacional de Aeronáutica Espacial (NASA), el Departamento de Defensa (USDOD) y la empresa Boeing, compartían los frutos de investigaciones efectuadas en común. A Boeing se le reconocía la titularidad de las invenciones y los derechos a la utilización de los datos para utilizarlos con fines comerciales, mientras USDOD obtenía una licencia exenta de regalías para aprovechar la tecnología únicamente "con fines gubernamentales" (véase ESTADOS UNIDOS. Medidas que afectan al comercio de grandes aeronaves civiles -segunda reclamación-WT/DS353/AB/R).

${ }^{21}$ Escribió Oscar Oszlak: "...En condiciones de fraccionamiento burocrático resultante de la descentralización y autonomización de funciones, la coordinación de actividades entre unidades se hace, o bien innecesaria, o bien imposible. Cada unidad tiende a funcionar dentro de comportamientos estancos aún cuando su actividad se encuentre técnicamente eslabonada a la de otras unidades. Esta feudalización del aparato estatal encuentra su principal explicación en la relación simbiótica que se establece entre agencias burocráticas y sectores organizados de la sociedad (Brown y Erie, 1979). En buena medida, estas agencias obtienen legitimidad y recursos movilizando clientelas influyentes, aunque a veces la vinculación se convierte en una virtual captura de las agencias por parte de sus clientelas (...) Dos fenómenos íntimamente conectados se derivan de estas condiciones de funcionamiento. Por una parte, una agencia cautiva de su clientela tiende inevitablemente a alterar su marco normativo formal, acomodándolo a los intereses de su clientela. Este fenómeno, variablemente conocido como "desplazamiento de objetivos" (Merton, 1940) o "bifurcación de propósitos" (Selznick, 1948), constituye en el fondo un mecanismo
} 
Revista Aportes para la Integración Latinoamericana Año XXIII, N 36/ Junio 2017, ISSN 2468-9912. DNDA: 5318259 en línea

Marcelo Halperin

Las empresas transnacionales en el escenario latinoamericano del capitalismo tardío

Págs. 1-43

Y por último no debe pasar desapercibido el caso del intervencionismo económico del Estado en China: las empresas estatales van tomando vuelo propio, hasta el punto que resulta problemática la caracterización como "públicas" por otros Estados que pretenden reaccionar ante sus prácticas predatorias en los mercados internacionales ${ }^{22}$. Hasta aquí el caso de China parece reducirse al de una cuestión probatoria en los procedimientos arbitrales, pero no sería aventurado conjeturar que realmente la gestión empresarial proyectada internacionalmente por entidades públicas chinas, las irá despegando progresivamente de las jerarquías burocrático-administrativas propias del Estado como tal.

de reducción de incertidumbre, en tanto permite a la agencia burocrática contar con los apoyos necesarios para asegurar su legitimidad y supervivencia" (Oscar Oszlak: "Políticas públicas y regímenes políticos; reflexiones a partir de algunas experiencias latinoamericanas". Estudios CEDES, volumen 3 número 2, 1980, páginas 37 y 38).

El texto de Oszlak transcripto más arriba se completa con notas de pie de página en las que indica que: (a) la captura de las agencias estatales por parte de sus clientelas describe la situación que S.N. Eisenstadt denomina "desburocratización"; (b) para un análisis del concepto de "captura clientelística" aconseja la lectura de Sabatier, P: "Social Movements and Regulatory Agencies: Toward a more adequate-and less pessimistic- theory of "clientele capture", Policy Sciences, 6: 301-302. (1975); (c) la referencia a Merton corresponde a: MERTON, Robert K.: "Bureaucratic Structure and Personality", Social Forces, vol. XVII, 1940; y (d) la de Selznick corresponde a: SELZNICK, Philip: "Foundations of the Theory of Organization", American Sociological Review, vol. 13, 1948.

${ }^{22}$ En el Sistema de Solución de Diferencias de la OMC resultó aleccionador el informe del Órgano de Apelación dentro del caso DS 437 "ESTADOS UNIDOS. Medidas en materia de derechos compensatorios sobre determinados productos procedentes de China". Finalmente no se hizo lugar a los derechos compensatorios aplicados por Estados Unidos contra importaciones originarias de China cuyos insumos habían sido adquiridos en origen mediante condiciones ventajosas a empresas de propiedad estatal. El Órgano de Apelación determinó que los beneficios supuestamente otorgados por el Estado chino debían ser objeto de prueba por el Estado Miembro que los cuestionaba (a la sazón, EUA) en los términos del artículo 14 apartado d) y artículo 1.1.b) del Acuerdo sobre Subvenciones y Medidas Compensatorias. Al efecto, correspondía tomar como referencia los precios que reflejaran las condiciones reinantes en el mercado del país de suministro, más allá de las constataciones acerca de lo que debía ser considerado estrictamente como "gobierno" u "organismo público" en el marco del Acuerdo. Este contundente informe fue adoptado por el Órgano de Solución de Diferencias el 16 de enero de 2015. El tema relativo al carácter "público" de las empresas chinas involucradas, ya había sido materia de análisis en el Grupo Especial, cuando los árbitros, interpretando el sentido que debía asignarse al concepto de "organismo público" en el Acuerdo sobre Subvenciones y Medidas Compensatorias, hicieron hincapié en que "organismo público" no es sinónimo de "empresa de propiedad estatal". El informe de esta primera instancia se había distribuido el 14 de julio de 2014. Las inquietudes despertadas por este tipo de controversia fueron expuestas entonces por Pedro da Motta Veiga: "Los subsidios chinos absueltos" (en portugués), diario O Estado de S. Paulo, sección Economía, 16 de mayo de 2011. 
Revista Aportes para la Integración Latinoamericana Año XXIII, N 36/Junio 2017, ISSN 2468-9912. DNDA: 5318259 en línea

Marcelo Halperin

Las empresas transnacionales en el escenario latinoamericano del capitalismo tardío

Págs. 1-43

g) El desarrollo de estrategias que, invocando los derechos de propiedad industrial contravienen otros derechos que a su vez los Estados nacionales deben garantizar a sus

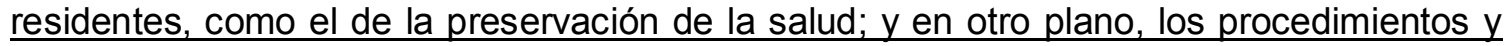
resultados provisionales de innovaciones tecnológicas encadenadas pueden perder la entidad requerida para su propia protección a título de propiedad industrial.

Por un lado, los derechos de propiedad intelectual son ejercidos e invocados con el objeto de acaparar los mercados a través del registro de patentes y licencias, dando lugar a conflictos de derechos cada vez más agudos debido al sustento humanitario de los cuestionamientos $^{23}$. Por otro lado, las necesidades de expansión suelen impulsar diversificaciones, concertaciones o acuerdos inter-empresariales que, cuando abordan actividades de investigación aplicada, van arrasando en la práctica con derechos de propiedad intelectual preexistentes y simultáneamente desarrollan innovaciones que, por la vorágine y opacidad de dichas actividades resultan de imposible reivindicación. Al respecto, entre las distintas modalidades de conversión o transformación del conocimiento organizacional, dos de ellas son potencialmente incompatibles con la posibilidad de ser conceptualizadas y por lo tanto no susceptibles de apropiación privada: la modalidad de socialización o pasaje de un conocimiento tácito a otro (por ejemplo, a través de las llamadas "tormentas de ideas"); y la interiorización organizacional de un conocimiento

\footnotetext{
${ }^{23}$ No es frecuente la lectura comparada de los artículos 7 y 8 del Acuerdo sobre los Aspectos de los Derechos de Propiedad Intelectual Relacionados con el Comercio (ADPIC en español; TRIPs en inglés) que fuera sancionado en la Ronda Uruguay del GATT. El autor lo intentó en su documento "América Latina en un tiempo de transfiguración de los Estados nacionales, los tratados de libre comercio y el orden multilateral" (publicado por la Revista Aportes para la Integración Latinoamericana, año XIV número 18, junio 2008). Allí se advirtió que conviene prestar atención al reconocimiento de los derechos de los Miembros para "promover el interés público en sectores de importancia vital para el desarrollo socioeconómico y tecnológico, siempre que esas medidas sean compatibles con lo dispuesto en el presente Acuerdo" (ADPIC artículo 8). De modo que bien podría interpretarse que la protección de los derechos de propiedad intelectual no siempre está por encima de la promoción de la innovación tecnológica y que, además "debe contribuir a ella" (conforme artículo 7). El principal punto de fricción entre un bien jurídico y otro ha sido hasta ahora el de la salud pública. En este aspecto, el derecho a los Estados Miembros para autorizar licencias "obligatorias" ( producir medicamentos, había resultado inoperante por la imposibilidad, en muchos países, de lograr condiciones adecuadas para dichas actividades productivas. De ahí el reconocimiento del problema en una Declaración de la Conferencia Ministerial en Doha relativa a la Salud Pública (sexto párrafo), luego la Decisión del Consejo General dada el 30 de agosto de 2003 y por último la incorporación de un nuevo artículo al Acuerdo ADPIC, en vigor desde el 23 de enero de 2017, que autoriza a los Estados Miembros a otorgar licencias obligatorias para la exportación de medicamentos genéricos a otros Estados Miembros con escasa o nula capacidad de producción.
} 
Revista Aportes para la Integración Latinoamericana Año XXIII, N³6/Junio 2017, ISSN 2468-9912. DNDA: 5318259 en línea

Marcelo Halperin

Las empresas transnacionales en el escenario latinoamericano del capitalismo tardío

Págs. 1 -43

explícito preexistente (por ejemplo, a través del "aprender haciendo"). Estas prácticas expuestas por I. Nonaka y $\mathrm{H}$. Takeuchi al analizar la evolución de corporaciones japonesas- son exacerbadas por las urgencias empresariales para innovar bajo condiciones de competencia que no dan respiro ${ }^{24}$.

\section{A PROPÓSITO DE LAS EMPRESAS BINACIONALES Y MULTINACIONALES DE CARÁCTER SUBREGIONAL EN AMÉRICA LATINA}

Recorriendo la nómina de prácticas que llevaban a cabo las ETN desde la segunda posguerra, incluyendo los entrecruzamientos operativos con organismos públicos o empresas estatales, según se sintetiza más arriba, puede ponerse en un contexto histórico el análisis de aquellos encuadramientos normativos destinados a contrarrestar esas acciones, regulando la creación y gestión de las empresas binacionales o multinacionales latinoamericanas con alcance subregional, así como la evaluación de las experiencias recogidas cuando dichos emprendimientos pudieron tener algún principio de ejecución.

El supuesto común es conocido: garantizando la propiedad y el control gerencial de una empresa subregional sería posible llevar a cabo las actividades alineadas a los objetivos de política económica con los que se pretendía justificar su creación.

De modo que las claves consistían en: (i) definir objetivos de política económica subregional, para cuya realización se debería contar con una actividad productiva que por distintos motivos las ETN no podrían satisfacer adecuadamente (o bien no deberían hacerlo, según el criterio político); y (ii) diseñar los mecanismos de propiedad y control empresarial más adecuados para llevar a cabo la actividad productiva deseada mediante la gestión de estas empresas subregionales.

\footnotetext{
${ }^{24}$ Véase Ikujiro Nonaka y Hirotaka Takeuchi: "La organización creadora de conocimiento", en especial el capítulo 3 (Teoría de la creación del conocimiento organizacional), Oxford University Press, editado en México, 1999.
} 
Revista Aportes para la Integración Latinoamericana Año XXIII, N 36/Junio 2017, ISSN 2468-9912. DNDA: 5318259 en línea

Marcelo Halperin

Las empresas transnacionales en el escenario latinoamericano del capitalismo tardío

Págs. 1-43

Entre las usinas de pensamiento que alentaron dichas iniciativas en África y América Latina el primer plano correspondió sin duda a la Conferencia de las Naciones Unidas sobre Comercio y Desarrollo (UNCTAD) ${ }^{25}$.

En América Latina el principal motivo de inspiración fue sin duda el Acuerdo de Cartagena firmado el 26 de mayo de 1969. Involucró a Bolivia, Chile, Colombia, Ecuador y Perú. Venezuela, que había figurado en las actividades preparatorias a título de observador, adhirió en 1973 y Chile acordó su retiro en 1976. Estas fechas resultan significativas porque marcaron la formación académica de una generación de intelectuales latinoamericanos y no sólo de los países involucrados en la iniciativa. El Acuerdo de Cartagena pasó a ser, rápidamente, objeto de culto. Representó una especie de apuesta política de aquel grupo de países "de desarrollo intermedio" para expandir y acelerar en sus relaciones recíprocas el proceso de integración económica encuadrado en ALALC. Pero las ambiciones no quedaron supeditadas a los temas de la liberalización comercial y a la pretensión de fijar un arancel externo común en el marco andino. ALALC convalidó, a través de la "declaración de compatibilidad" dada por su Comité Ejecutivo, algo mucho más relevante. El Acuerdo de Cartagena fue sinónimo de una estrategia de desarrollo compartido sobre la base de programas sectoriales de desarrollo industrial junto a la adopción de un régimen común para el tratamiento de los capitales extranjeros, a la transferencia de tecnología y propiedad industrial. $Y$ no fueron metas programáticas, sino la regulación puntillosa de un programa cuya operatividad estuvo respaldada

\footnotetext{
${ }^{25}$ Enmarcada por la Conferencia de las Naciones Unidas sobre Comercio y Desarrollo (UNCTAD), la Comisión de Cooperación Económica entre Países en Desarrollo aprobó un programa de trabajo del que se surgieron distintos informes elaborados por la Secretaría. Uno de los más ilustrativos fue el editado el 7 de mayo de 1979 con el título: "Regímenes jurídicos para la creación de empresas multinacionales entre países en desarrollo establecidos por agrupaciones de integración y cooperación económica" (catalogado TD/B/C.7/30). Años antes, ya Félix Peña había advertido: "(...) existe una tendencia muy fuerte a resenvar la denominación de "empresa multinacional latinoamericana" (o andina, o centroamericana, a nivel subregional) para aquellas de mercado, capital y centro de decisión multinacional, en la medida en que, además, quienes controlen dicho capital y los órganos de dirección y de gestión sean latinoamericanos. El tipo ideal de "empresa multinacional" en América Latina tiende a identificarse, así, con aquella que es multinacional por su mercado su capital y su centro de decisión y latinoamericana por su control real" (Félix Peña: "Empresas binacionales y multinacionales latinoamericanas: ideas en torno a algunos de sus aspectos jurídicos", publicado en la revista Derecho de la Integración número 13, julio 1973, Instituto para la Integración de América Latina, Banco Interamericano de Desarrollo, página 22. Según indicó el autor, "en parte, enfoques e ideas presentados en este artículo se han beneficiado del trabajo conjunto que venimos desarrollando desde hace un tiempo con Eduardo White y Susana C. de Zalduendo, miembros del Sector Jurídico del INTAL").
} 
Revista Aportes para la Integración Latinoamericana Año XXIII, N 36/Junio 2017, ISSN 2468-9912. DNDA: 5318259 en línea

Marcelo Halperin

Las empresas transnacionales en el escenario latinoamericano del capitalismo tardío

Págs. 1-43

institucionalmente, bajo la inspiración del ejemplo europeo. Se incluyeron dosis nada desdeñables de supranacionalidad, en cabeza tanto del órgano comunitario (la Junta) como mediante la consagración del Tribunal de Justicia, quedando en este caso asegurada la cohesión comunitaria mediante: el control de legalidad; y el régimen de pronunciamientos prejudiciales para fijar interpretaciones jurídicas uniformes. Vista desde aquellas cumbres fundacionales, la historia de la Comunidad Andina no puede ser entendida sino como un proceso de progresiva degradación de sus objetivos dadas las crecientes dificultades, a medida que transcurría el tiempo, para llevar a la práctica programas colectivos que implicaran asignación de factores y recursos ${ }^{26}$.

En sintesis, algunas preocupaciones básicas alentaron los proyectos relativos a la creación de empresas binacionales o multinacionales catalogadas como sub-regionales, a saber: (a) una convicción sobre las amenazas potenciales que representaban las ETN para el desenvolvimiento de políticas autónomas en los países latinoamericanos donde podían asentarse sus filiales o subsidiarias ${ }^{27}$; y (b) otra convicción, igualmente sólida, sobre la necesidad de acordar, entre países en desarrollo vecinos o pertenecientes a las mismas sub-regiones, las reglas adecuadas para componer y luego proteger mercados extendidos a través de uniones aduaneras. Estos esquemas de integración comercial

\footnotetext{
${ }^{26}$ Más aún, en la esfera estrictamente comercial los términos de las relaciones internacionales externas de los países miembros llevaron a la sistemática perforación de la cláusula de la nación más favorecida (NMF). Al pronunciarse el 11 de junio de 1998, la Secretaría General de la Comunidad Andina daba cuenta de ello con un tono patético: "...la Secretaría General considera que, con excepción de Bolivia, quien ha desgravado la totalidad de su universo arancelario con los cinco países miembros, los otros cuatro se encuentran actualmente en situación de incumplimiento, bien sea porque han sujetado el cumplimiento del artículo 155 a una condición de reciprocidad que es ajena a la mencionada obligación jurídica, cuya aplicación debe ser inmediata e incondicional o bien porque simplemente no se le ha considerado a los efectos de la desgravación arancelaria" (informe al nonagésimo período extraordinario de sesiones de la Comisión, 11 de junio de 1998).

${ }^{27}$ Lo señalaba el mismo Félix Peña: (a propósito de las ETN) "El hecho de que las mismas se han convertido no en el único pero posiblemente en el más importante marco institucional para la transferencia internacional de recursos productivos, y en particular, de tecnología y de capacidad empresarial. Siendo así, la corporación internacional puede ser visualizada como el principal agente de una preocupante tendencia a la bisegmentación del sistema internacional, entre países productores de tecnología original y países consumidores o simples adaptadores de tecnología" (...) "La aceptación del hecho de que una corporación internacional es un centro regulador del comercio internacional que puede tornar en inefectivas las reglas nacionales o internacionales desde el momento en que transforman en "comercio interno" el flujo de bienes, debe ser el punto de partida para el replanteo de las posiciones de los países en desarrollo dentro de los grandes foro comerciales internacionales" (obra citada, páginas 16 y 17).
} 
Revista Aportes para la Integración Latinoamericana Año XXIII, N 36/ Junio 2017, ISSN 2468-9912. DNDA: 5318259 en línea

Marcelo Halperin Las empresas transnacionales en el escenario latinoamericano del capitalismo tardío Págs. 1-43

debían respaldar el desenvolvimiento de las nuevas empresas binacionales o multinacionales proyectadas precisamente para el aprovechamiento de lo acordado.

Pasados algunos años desde aquellas edificaciones de política económica, parece instructiva una referencia sobre sus implicaciones ideológicas. Las ETN, catalogadas por su voracidad para la conquista de mercados, supuestamente sólo podían ser neutralizadas con la misma medicina, esto es, contraponiéndoles al modo de políticasespejo a empresas dotadas de recursos equiparables y garantizando a estas últimas el acceso al mercado protegido. Sin embargo, había que contar con un obstáculo insalvable: el principio de no discriminación, piedra basal del multilateralismo. Las expresiones comerciales del principio de no discriminación no podían ser vulneradas, esto es, las cláusulas de la nación más favorecida y el trato nacional. En consecuencia, cualquier ETN podía igualmente aprovechar los beneficios del mercado subregional protegido por la unión aduanera mediante la radicación en ese territorio de sus filiales o subsidiarias. Por eso la protección del mercado subregional debía reforzarse a través de los regímenes de inversión extranjera ${ }^{28}$ y contemplando la participación de los propios Estados (en tanto miembros del esquema de integración subregional), en la composición del capital societario de las empresas binacionales o multinacionales previstas ${ }^{29}$. Resultaba entonces un cuadro con la más alta

\footnotetext{
${ }^{28}$ Haciendo historia, cabe recordar que en la Comunidad Andina, a fin de promover la generación de empresas multinacionales subregionales, la Decisión número 46 complementó a la Decisión número 24 resultando un régimen que reconocía a los inversionistas andinos (quienes debían participar en estas empresas en una proporción no inferior al sesenta por ciento del capital) ciertas ventajas especiales relativas a las transferencias de dicho capital (no obligación de transferencia a inversionistas nacionales) y a las utilidades (previa autorización del organismo nacional competente, podían transferir al territorio de origen de los capitales, las utilidades netas provenientes de la inversión directa, previo pago de los impuestos correspondientes).

A su turno, el Convenio de Industrias Centroamericanas de Integración no incluyó disposiciones relativas al control y porcentaje de participación de capital originario de Centroamérica en la propiedad de las empresas, sino que delegó estas precisiones en los respectivos protocolos a ser sancionados con motivo de la aprobación de los distintos proyectos industriales. Así, el Primer Protocolo, referido a la industria de soda cáustica e insecticidas clorados, estableció que el capital social debía ser ofrecido en venta a inversionistas centroamericanos en al menos un cuarenta por ciento del total. En cambio, el Segundo Protocolo, relativo a la creación de una industria para la fabricación de vidrio plano o en lámina, dispuso que la empresa habría de estar constituida inicialmente por capitales de origen centroamericano en una proporción no menor al sesenta por ciento, bajo títulos nominativos y debiéndose respetar esa proporción en todo momento, inclusive con motivo de un aumento ulterior de ese capital social.

${ }_{29}$ Siguiendo con la crónica histórica, en la CARICOM el régimen de promoción de empresas subregionales, si bien tuvo por objeto la fijación de un sistema preferencial, no hizo diferencias
} 
Revista Aportes para la Integración Latinoamericana Año XXIII, N 36/Junio 2017, ISSN 2468-9912. DNDA: 5318259 en línea

Marcelo Halperin

Las empresas transnacionales en el escenario latinoamericano del capitalismo tardío

Págs. 1-43

protección posible, mediante: obstáculos comerciales (arancelarios y no arancelarios) que delimitaban las uniones aduaneras; regulación de la inversión extranjera; e intervención de los Estados nacionales en la organización y gestión de las empresas binacionales o multinacionales alineadas con políticas económicas también acordadas a escala subregional.

\section{QUÉ CAMBIÓ EN LA OPERATORIA COMERCIAL Y EN LAS REGULACIONES MULTILATERALES}

El sueño de la protección comercial a través de las uniones aduaneras entre países de la periferia fue barrido por las condiciones de producción en la economía global ${ }^{30}$. Esas mismas condiciones han implicado un cambio sustancial tanto en el contenido de los papeles desempeñados por las ETN como en el contenido de los papeles desempeñados

entre la participación en los emprendimientos de empresas públicas o privadas. En mayo de 1976 ministros de finanzas de países caribeños aprobaron un régimen alusivo pero que fue firmado por la mayoría de los los Jefes de Estado o sus representantes recién durante 1988: "The Agreement for the Establishment of a Regime for CARICOM Enterprises", que según un informe de CEPAL habría entrado en vigor en octubre de aquel mismo año. Los conceptos surgen de las definiciones establecidas por el artículo 1: "NATIONAL INVESTOR means (...) a Member State or a national of a Member State holding equity share capital of a Company". Más adelante resalta la significación otorgada al "control" y no tanto a la "propiedad" de las empresas: "REGIONALLY-OWNED AND CONTROLLED in relation to a Company means that the company is one in which in the opinión of the Authority nationals of at least two Member States exercise management and control beneficially owning shares carrying between them directly or indirectly".

El Convenio de las Industrias Centroamericanas de Integración presenta otro aspecto de interés con respecto al diseño del mecanismo de promoción: el criterio para la asignación de los proyectos entre los distintos Estados de la subregión. Según los protocolos, ningún país podía ser adjudicatario de una segunda planta de producción hasta que no se hubiera adjudicado por lo menos una a todos los demás países. El documento de UNCTAD citado más arriba, da cuenta sin embargo de una interpretación del Consejo Económico Centroamericano efectuada en el año 1964, por la cual se restringió esta cláusula indicándose que la prohibición estaba circunscripta a las plantas de "un mismo ramo industrial", por lo cual en un Estado centroamericano podían asentarse diversas plantas pertenecientes a un mismo proyecto amparado por el régimen, sin necesidad de otras instalaciones previas en los demás Estados de la subregión y toda vez que se tratara de plantas para la producción de bienes en ramos industriales distintos.

${ }^{30} \mathrm{El}$ autor ha creído constatar que al cabo de un período de más de cincuenta años de multilateralismo e integración económica, desde distintos ángulos es fácil advertir una progresiva erosión de aquella fantasía política de racionalidad, consistencia o coherencia imputada al sistema económico internacional e hipotéticamente plasmada por el orden multilateral y los formatos de integración. Ahora el objeto material de la integración es distinto al originariamente diseñado porque no se trata de profundizar ni acelerar los tiempos de expansión de mercados, sino todo lo contrario: acompasar, administrar estos tiempos sobre bases de reciprocidad. Véanse los argumentos expuestos en tal sentido en: "Propuestas para una sociología del conocimiento de la integración económica", en el libro "Estrategias de inserción internacional e integración latinoamericana en el siglo XXI" editado por Noemí B. Mellado e impreso por Lerner ed., Córdoba, Argentina, 2015. 
Revista Aportes para la Integración Latinoamericana Año XXIII, N³6/Junio 2017, ISSN 2468-9912. DNDA: 5318259 en línea

Marcelo Halperin

Las empresas transnacionales en el escenario latinoamericano del capitalismo tardío

Págs. 1-43

por los Estados nacionales. Y, desde otro ángulo, han implicado un cambio, también sustancial, en la relación entre ambos tipos de entidades.

En la década del setenta J. Habermas difundió el concepto de "capitalismo tardío" al vislumbrar, como pocos, el aumento de la complejidad de los sistemas sociales en tanto derivación del proceso de acumulación en un estado avanzado del modo de producción capitalista. Simultáneamente tomó nota de sus principales implicaciones: en el primer plano la necesidad política de introducir "compensaciones" sociales para disimular lo que irónicamente el mismo Habermas llamó "fallas del mercado"; y en otro plano, quizás menos visible, la necesidad también política de preservar códigos de comunicación y legitimación aptos para asimilar ese "crecimiento exponencial de la complejidad del sistema" 31

Ya en los setenta las ETN tenían estructuras organizativas, orientaciones estratégicas y modelos de gestión que difieren de las estructuras, orientaciones y modelos que caracterizan a las ETN en las primeras décadas del siglo XXI. Estas transformaciones deben imputarse a la agudización de la competencia para sobrellevar, en tiempos que se acotan y espacios que se expanden, las articulaciones en cadenas de valor. Cada uno de los eslabones de la cadena puede quebrarse intempestivamente por eventualidades tales como la irrupción de nuevas oleadas tecnológicas o la volatilidad financiera. Para interpretar la entidad de dichos problemas en los que están envueltas las ETN durante esta fase del capitalismo tardío (es decir, cuando se ven obligadas a mantener una estrecha relación con los Estados nacionales donde asientan las matrices y sus filiales o subsidiarias), es preciso atender a dos cuestiones superpuestas: las referidas a cadenas de valor y en esas condiciones las características del comercio intra-firma ${ }^{32}$.

31 J. Habermas: "Problemas de legitimación en el capitalismo tardío", Amorrortu editores y
Ediciones Cátedra S.A., Madrid 1999, páginas 84 y 100 .
32 En un instructivo documento editado en el año 2014 , la CEPAL indicaba que para entonces "(...)
gran parte del comercio y de la producción mundial se lleva a cabo dentro de las llamadas cadenas
de valor, ya sean regionales o globales. Según estimaciones de la UNCTAD, cerca de un $80 \%$ de
las exportaciones mundiales de bienes y servicios (medidas en valor bruto) corresponde a
comercio en cadenas de valor, asociado a la participación de empresas multinacionales (...) El
comercio en cadenas de valor presenta varios rasgos distintivos. El primero es su estrecha relación
con la inversión extranjera directa. Existe una alta correlación positiva entre el acervo de IED de los
países y su participación en cadenas de valor. Esta correlación se ha hecho más marcada en las
últimas dos décadas, especialmente en los países menos desarrollados (...) En segundo lugar, 
Revista Aportes para la Integración Latinoamericana Año XXIII, N 36/Junio 2017, ISSN 2468-9912. DNDA: 5318259 en línea

Marcelo Halperin

Las empresas transnacionales en el escenario latinoamericano del capitalismo tardío

Págs. 1-43

Con respecto a los Estados nacionales, especialmente en países en desarrollo, afloran rigideces estructurales asociadas a la marginación y desplazamiento de poblaciones acosadas por sustituciones tecnológicas y el consiguiente ahogo financiero por el aumento del gasto público destinado a inhibir la "desobediencia civil". Sin embargo, aun en las peores condiciones, los residentes marginados y desplazados, merced a las asignaciones sociales dinerarias son compelidos a consumir los frutos de la tecnología disponible ${ }^{33}$.

En resumen: para ambos tipos de entidades ya es notoria la potencial inviabilidad de organizaciones, estrategias y gestiones o procesos sostenidos por conducciones centralizadas y por lo tanto con dificultades para realimentarse según los resultados del desempeño. Así, tanto las ETN como los Estados nacionales que subsisten como tales es porque todavía están en condiciones de afrontar, de algún modo, las disrupciones tecnológicas y la volatilidad financiera que caracterizan a la economía global en esta fase de su desarrollo, reajustando (como pueden) sus organizaciones, estrategias y gestiones o procesos de manera sistemática y constante. A su vez, tales realimentaciones y reajustes son la consecuencia de su misma interacción: las ETN y los Estados nacionales actúan como protagonistas de un juego interactivo que los enlaza disciplinariamente a través de una composición de fuerzas en tensión, a título de inseparables "partenaires".

este tipo de comercio se caracteriza por un intenso intercambio de bienes intermedios (...) Un tercer rasgo es el aumento del contenido importado de las exportaciones (...) Un cuarto elemento distintivo del comercio en cadenas de valor es el rol fundamental que cumplen una amplia gama de servicios..." ("Integración Regional. Hacia una estrategia de cadenas de valor inclusivas", documento de CEPAL, 2014, página 42). Con respecto a la región, el mismo documento advertía que "(...) Pese a la alta presencia de las manufacturas en el comercio intrarregional de América Latina y el Caribe, la mayor parte de ella corresponde a intercambios de bienes finales, como lo evidencia la reducida participación de los bienes intermedios (partes y componentes). Esta solo alcanza al $10 \%$ del valor del comercio entre los países de la región, mientras que entre los países de la "fábrica Asia" supera el $30 \%$ de los intercambios..." (obra citada, página 62). A su vez, las cadenas de valor dan lugar a un intenso comercio intra-firma. En tal sentido, la Organización Mundial del Comercio (OMC) lo reflejaba en sus cuadros estadísticos incorporados al informe correspondiente al año 2013, al detectar que por ejemplo un tercio de los suministros de las filiales de ETN de origen estadounidense, ya eran objeto de intercambio dentro de las mismas empresas (conforme Organización Mundial del Comercio: Estadísticas del comercio internacional 2013, página 187).

${ }_{33}$ Véase, del autor: "Consecuencias del despoblamiento rural y la desorganización social en América Latina" en "Latinoamérica: inserción global e integración regional", libro dirigido y editado por Noemí Mellado, editorial Lerner, Córdoba, Argentina, 2016. 
Revista Aportes para la Integración Latinoamericana Año XXIII, N 36/Junio 2017, ISSN 2468-9912. DNDA: 5318259 en línea

Marcelo Halperin Las empresas transnacionales en el escenario latinoamericano del capitalismo tardío

Págs. 1-43

A partir de las condiciones mundiales en la segunda posguerra, en tanto actores centrales de los procesos de expansión de mercados y concentración de la propiedad y el control de los medios de producción, las ETN merecieron ser consideradas como una amenaza por los Estados nacionales de la periferia. De todos modos, el capital se reproducía a un ritmo tal que la competencia no ponía en riesgo fácilmente la subsistencia de las ETN. Estos márgenes de previsibilidad promovían la burocratización de sus cuadros directivos y hasta cierto punto respaldaban la continuidad de las cúpulas y la provisión de financiamiento. Así, la puja por los mercados no tenía tanto dramatismo y en consecuencia los Estados nacionales donde se hospedaban las filiales y subsidiarias de las ETN -también hasta cierto punto- podían lidiar con sus pretensiones. Por ejemplo, en un reconocido estudio que relevó el vínculo del Estado argentino con filiales de ETN, los autores debieron atender a una tipología, usualmente utilizada en análisis comparativos, que distinguía a las filiales de ETN según el grado de vinculación con las matrices desde el punto de vista de su autonomía operativa. ${ }^{34}$ Es evidente que a la luz de las condiciones de intercomunicación vigentes en las primeras décadas del siglo XXI aquella tipología quedó reducida a una curiosidad histórica.

En síntesis, la aceleración progresiva del ritmo impuesto al capital reproductivo introdujo una alteración sistémica. Las sucesivas oleadas de innovaciones tecnológicas sobre las cuales viene cabalgando la reproducción del capital a un mismo tiempo van modificando las propias organizaciones, sus estrategias y programas productivos.

Los procesos de reproducción del capital tienen un ritmo cada vez más acelerado. ${ }^{35}$ Enfocando estos cambios desde el ángulo de la actividad organizacional resulta tentador

\footnotetext{
${ }^{34}$ El documento de referencia es: "Apertura y Estrategia de las Empresas Transnacionales en la Industria Argentina" de Bernardo Kosacoff y Fernando Porta, publicado en el libro editado por B. Kosacoff: "Estrategias empresariales en tiempos de cambio. El desempeño industrial frente a nuevas incertidumbres", Bernal, Universidad Nacional de Quilmes/CEPAL, 1998. Los autores relativizaron con razón el valor heurístico de la tipología utilizada por los trabajos de Dunning $(1988,1994)$ y reflejada entonces en documentos de la UNCTAD $(1992,1995)$. Esta construcción, de uso corriente todavía en las últimas décadas del siglo XX distinguía las modalidades interactivas entre las matrices y sus respectivas filiales (véase la obra citada, páginas 74 y 75).

${ }^{35}$ La caracterización de K. Marx parece más vigente que nunca: "El desarrollo de la producción capitalista exige un constante crecimiento del capital colocado en una empresa, y la competencia impone las leyes inmanentes de la producción capitalista como leyes coercitivas exteriores a cada uno de los capitalistas. No le permite conservar su capital sin aumentarlo, y no puede seguir aumentándolo sin una acumulación progresiva" ("El Capital, capítulo XXIV "Conversión de la plusvalía en capital", página 566, Editorial Cartago, Libro primero, Buenos Aires 1973). Véase
} 
Revista Aportes para la Integración Latinoamericana Año XXIII, N³6/Junio 2017, ISSN 2468-9912. DNDA: 5318259 en línea

Marcelo Halperin

Las empresas transnacionales en el escenario latinoamericano del capitalismo tardío

Págs. 1 -43

un ejercicio de extrapolación para desagregar dicha cadencia febril en dos componentes, a los que suele hacerse alusión con frecuencia: "rutinas" y "sorpresas" o "sobresaltos". El "ritmo" sería entonces una secuencia repetida de saltos o quiebres tecnológicos que implicarían el pasaje de una a otra rutina. Se supone así que las oleadas de innovación tecnológica representarían sorpresas o sobresaltos que introducirían en las rutinas el efecto de progresivas aceleraciones. Sin embargo, sugiero que semejante desagregación conceptual simplifica el entendimiento hasta distorsionarlo. Al respecto, he intentado demostrar en otro trabajo que los procesos productivos, en esta fase de la economía global van siendo atravesados no por disrupciones masivas sino por disrupciones parciales y sucesivas en las distintas etapas del camino crítico (por sustitución de materias primas o insumos; o por sustitución de instrumentos o dispositivos aplicados directa o indirectamente sobre dichos procesos). En tales condiciones, recrudecen día a día las exigencias de competitividad. Por ello el régimen de rutinas no cambia de manera sustancial y periódicamente, sino que el trabajo debe readaptarse cada día y bajo un síndrome de incertidumbre que finalmente ha terminado por desacreditar aquella concepción sobre supuestas alternancias de rutinas y sorpresas o sobresaltos ${ }^{36}$.

Desde el punto de vista de los dispositivos regulatorios, las disciplinas del GATT -que, como es sabido, resultaron muy elementales- habían sido diseñadas para un mundo en el cual las relaciones económicas internacionales giraban esencialmente en derredor de los gravámenes aplicados al comercio de bienes físicos. Por contraposición no eran objeto de regulación multilateral distintos tipos de medidas no arancelarias, ni las implicaciones del comercio de bienes intermedios (regímenes desagregados o específicos de origen); ni el comercio de servicios en sus múltiples variedades; ni los flujos de

también, en el capítulo XXV del mismo Libro primero, titulado "Ley general de la acumulación capitalista" una descripción sobre las tendencias a la concentración y fragmentación del capital social que presenta llamativa semejanza con las tendencias observadas en la actualidad.

${ }_{36}$ Desde antes de la década de los sesenta, cuando comenzó a difundirse la producción automatizada con sus requerimientos de profesionalización para quienes debían monitorear esos procesos, surgieron también las preocupaciones teóricas sobre la necesidad de atender a "las condiciones exteriores" (P. Naville, 1961) o "el mundo exterior" (M. Crozier, 1956) desde las organizaciones hasta entonces fuertemente burocratizadas. Véase, al respecto: Pierre Naville: "EI progreso técnico, la evolución del trabajo y la organización de la empresa", en Georges Friedmann y Pierre Naville: "Tratado d Sociología del Trabajo", volumen I, Fondo de Cultura Económica, México, 1963, página 420. 
Revista Aportes para la Integración Latinoamericana Año XXIII, N 36/Junio 2017, ISSN 2468-9912. DNDA: 5318259 en línea

Marcelo Halperin

Las empresas transnacionales en el escenario latinoamericano del capitalismo tardío

Págs. 1-43

inversiones. La aceleración en el ritmo de reproducción del capital en manos de las ETN se llevó a cabo, precisamente, avanzando sobre aquellos vacíos regulatorios.

La aceleración productiva vinculada al ritmo de reproducción del capital en la economía internacional desató una puja por la conquista de mercados que a su vez obligó a los Estados de los países centrales a adoptar medidas desordenadas, ofensivas y defensivas según la percepción política acerca de las ventajas o desventajas competitivas $\mathrm{y}$, en todo caso, fuera del orden multilateral instituido. Fueron las épocas catalogadas como "zona gris", antes y después de la Ronda Tokio del GATT. ${ }^{37}$ Las iniciativas latinoamericanas para erigir empresas binacionales y multinacionales subregionales, tienen directa relación con la incertidumbre ocasionada por las prácticas extorsivas mediante las cuales los Estados refrendaban presiones de las ETN para imponer restricciones comerciales en ausencia de adecuadas disciplinas multilaterales. Precisamente, tanto la Ronda Tokio como también la Ronda Uruguay de donde emergió la OMC, fueron esperadas con optimismo por los países en desarrollo a la espera de regulaciones generadoras de una mayor previsibilidad.

\section{IV.¿Y AHORA QUÉ?}

\footnotetext{
${ }^{37}$ Los tiempos de la segunda posguerra estuvieron marcados por etapas de una mayor discrecionalidad en las políticas comerciales y que dieron lugar a imposiciones de unos países sobre otros para concertar compromisos destinados a la auto-restricción de exportaciones ("voluntary export restraints") y al establecimiento de límites en el acceso a los mercados ("orderly marketing arrangements"). Las legislaciones internas, tanto de Estados Unidos de América (EUA) como de la Comunidad Europea (CE), convalidaron estas prácticas a través de previsiones para adoptar represalias comerciales (en EUA "U.S. Trade Act Section 301" de 1974 y luego reforzada por un mecanismo de retaliación cruzada mediante "U.S. Trade Act Section "Super" 301 de 1988; y en la CE "Regulation 2641/84").

Estas prácticas abarcaron buena parte de la década del setenta (la Ronda Tokio comenzó en 1973 pero sus resultados se formalizaron recién en 1979); y también la década comprendida por el segundo quinquenio de los ochenta y el primero de los noventa (la Ronda Uruguay se abrió en 1986 y finalizó en 1994). Así, la concertación multilateral pareció llegar recién con la puesta en vigencia de los acuerdos de la OMC en 1995, cuyo significado surge de algunas frases incidentales, como las contenidas en los párrafos 1 y 3 del artículo 11 del Acuerdo sobre Salvaguardias: “...ningún Miembro tratará de adoptar, adoptará ni mantendrá limitaciones voluntarias de las exportaciones, acuerdos de comercialización ordenada u otras medidas similares respecto de las exportaciones o las importaciones (...) Los Miembros no alentarán ni apoyarán la adopción o el mantenimiento, por empresas públicas o privadas, de medidas no gubernamentales equivalentes a las medidas a que se hace referencia..."
} 

Año XXIII, N³6/Junio 2017, ISSN 2468-9912. DNDA: 5318259 en línea

Marcelo Halperin

Las empresas transnacionales en el escenario latinoamericano del capitalismo tardío

Págs. 1 -43

Acerca de las actividades productivas que se expanden más allá de un mismo asentamiento territorial-nacional, se suele distinguir, por un lado, la propiedad y el control patrimonial de las empresas tal como son presentados a los efectos fiscales y tributarios; y, por otro lado, la conducción y gestión de procesos involucrados en la actividad a distancia, esto es, la planificación y gestión de actividades productivas interdependientes, incluyendo: el camino crítico; la logística y las conexiones en materia de telecomunicaciones y transporte; y, en definitiva, la configuración y reconfiguración de las redes a través de las cuales cada empresa produce, distribuye y comercializa sus resultados a escala internacional. Adicionalmente habría que tomar nota de dos desagregaciones: (a) la desagregación de la propiedad al comercializarse el capital social en los mercados financieros; y (b) la desagregación del control operativo al profesionalizarse la dirección y la gestión.

Pero adecuando estas figuras jurídicas y organizativas a lo que ocurre en nuestros días, queda en claro que tanto la tenencia de un paquete accionario mayoritario como la institucionalización del control de los procesos a través de cuadros gerenciales, pueden significar poco y nada si se los concibe como resorte o sustento de la proyección internacional de cualquier ETN. El recorrido es inverso al sugerido por las figuras indicadas más arriba: la proyección internacional depende del desempeño de distintas operaciones que a su vez van determinando el valor de mercado de una empresa y por lo tanto tienden a formalizarse, siempre transitoriamente, bajo el régimen de propiedad y control que satisfaga dichos desempeños. Es así que los formatos contractuales, asociativos o societarios entre ETN y también entre ETN y dependencias estatales, pueden dar lugar a la absorción de una ETN por otra o a la fractura y descomposición de una ETN y eventualmente a su reemplazo por otra u otras. Estos cambios no deben examinarse como una cuestión previa a sus modalidades operativas sino, por el contrario, como una consecuencia de dichas modalidades operativas. La extrema fluidez que debe imprimirse a las actividades se refleja en que, por ejemplo,, la conocida distinción entre "grupos económicos" y "empresas" tiende a diluirse por su inoperatividad, a menos que se denomine descriptivamente "grupo económico" a una empresa en tanto apropiadora o controladora de otra. En tales casos, la relación entre el grupo económico y la empresa sometida, en la 
Revista Aportes para la Integración Latinoamericana Año XXIII, N 36/ Junio 2017, ISSN 2468-9912. DNDA: 5318259 en línea

Marcelo Halperin

Las empresas transnacionales en el escenario latinoamericano del capitalismo tardío

Págs. 1-43

práctica es semejante a la observada entre el vértice de conducción de una empresa y cualquiera de sus departamentos o secciones ${ }^{38}$.

Por lo demás:

En la delimitación de las relaciones con las filiales, cabe recordar un problema: no siempre es claro el límite que separa las grandes corporaciones entre sí. En años recientes se han difundido una serie de prácticas, consistentes en la profusión de arreglos colaborativos entre diferentes empresas transnacionales, comprendiendo la concesión de licencias cruzadas, la creación de empresas conjuntas, el diseño de programas de investigación y desarrollo en común, los acuerdos de abastecimiento de largo plazo, etc. Como resultado de estas transformaciones, ni la actividad ni el control ejercido por una empresa transnacional se identifican ya exclusivamente con sus flujos de inversión extranjera directa, planteándose un conjunto de problemas conceptuales y metodológicos que no tienen solución fácil. Las empresas conjuntas, o a veces sólo importantes operaciones conjuntas, generan relaciones con diversos grados de cercanía, y donde el control se comparte con otros centro de decisión. Los criterios usuales de participación en el capital sobre filiales formalmente establecidas no alcanzan a describir adecuadamente esta nueva situación ${ }^{39}$.

Cabe inferir que la aceleración del ritmo de expansión de mercados y concentración de factores y recursos en el capitalismo tardío trae consigo una agudización o afinamiento en las estrategias de supervivencia colectiva, empezando por la propia organización del capital, esto es, las ETN. Pero estos procesos comparten una misma inspiración teórica con la perspectiva utilizada por científicos naturales y sociales al trabajar con distintos materiales. En efecto, una variedad de hallazgos en áreas de la biología, física, química y cibernética desde la segunda mitad del siglo XX, han derivado epistemológicamente en una nueva forma de aproximación a los objetos bajo análisis. En tal sentido, se revalorizó el papel de organismos y de sistemas inorgánicos en tanto asimiladores o reductores del desorden o el caos contextual a través de una capacidad operativa que aumentaría en la medida de la propia complejidad interna de dichos organismos y sistemas. En el curso de los eventos o procesos de absorción o reducción del desorden o caos contextual los organismos y sistemas encontrarían las claves para su propia reformulación o enriquecimiento progresivo, siempre hacia una mayor complejidad. De allí que a partir de

\footnotetext{
${ }^{38}$ Raúl Trajtenberg cita, en tal sentido, la enumeración de modalidades de control por parte de los grupos económicos que utiliza Edward S. Herman: "Corporate control, corporate power" en Cambridge University Press, Cambridge 1981. Véase: Raúl Trajtenberg: "El concepto de empresa transnacional", Universidad de la República, Facultad de Ciencias Sociales, Departamento de Economía, documento de trabajo número 10/99m agosto 1999, página17.

${ }^{39}$ Raúl Trajtenberg, obra citada, página 23. El autor menciona como una de sus fuentes al documento "Transnational corporations in world development: trends and prospects", Center on Transnational Corporations, United Nations, New York 1988.
} 
Revista Aportes para la Integración Latinoamericana Año XXIII, N³6/Junio 2017, ISSN 2468-9912. DNDA: 5318259 en línea

Marcelo Halperin

Las empresas transnacionales en el escenario latinoamericano del capitalismo tardío

Págs. 1-43

estas concepciones el estudio sobre sujetos o unidades en interacción pasa a ser esencialmente el estudio de las transformaciones producidas con motivo de la misma interacción.

Al trasladar esta perspectiva al análisis organizacional, resulta que a propósito de un vínculo entre organizaciones ya no cabe atender a la organización bajo parámetros que privilegien el orden (como en el modelo tradicional de las organizaciones burocráticas) sino que ahora el foco queda centrado en las respectivas unidades que protagonizan el vínculo. Es decir: por un lado el concepto de interacción desplaza operativamente al concepto de orden y, por otro lado, el centro de atención no se posa sobre cada una de las organizaciones involucradas sino sobre las secciones o departamentos que protagonizan la interacción ${ }^{40}$. El tratamiento en Brasil de las relaciones entre agencias estatales y empresas privadas ha seguido un enfoque similar, en las últimas décadas del siglo XX, bajo el nombre "Estado en acción"41.

Siguiendo esta línea, parece anticuada la concepción y evaluación de las ETN según su envergadura patrimonial y organizacional como si la dotación de factores y recursos fuera la clave para obtener determinada participación en los negocios mundiales de un determinado rubro. En cambio, hoy día las ETN deberían caracterizarse más bien como pólipos cuyo secreto de subsistencia reside en el movimiento articulado de sus extremidades. Más aún, la inteligencia de la ETN ya no está concentrada en una cabeza que suministra directivas unidireccionales, sino que las distintas operaciones responden a procedimientos intelectivos que son propios de cada tipo de operación y que aún pueden modificar los procedimientos aplicados en otras

\footnotetext{
${ }^{40}$ Conforme Morin, Edgar: "Ciencia con conciencia" (versión en portugués, Lisboa, Europa-América 1982, páginas 73, 142 y 143, citado por Mauricio Serva: "El paradigma de complejidad y el análisis organizacional", Revista de Administración de Empresas de la Fundación Getulio Vargas volumen 32 número 2, abril-junio 1992, también en portugués). Desde otro ángulo, N.N. Taleb advierte que los organismos y sistemas complejos pueden superar sus encrucijadas de supervivencia mediante la reformulación de funciones secundarias, idea que bien puede proyectarse sobre las ETN que frecuentemente deben alterar sustancialmente el orden jerárquico de su departamentalización interna cuando sustituyen procesos y productos (véase: Nassim Nicholas Taleb: "El cisne negro, EI impacto de lo altamente improbable", editorial Paidos, 2014, Barcelona, España, páginas 415 y 416).

${ }^{41}$ Mauricio Serva: "El paradigma de complejidad y el análisis organizacional", citado, página 31. Aquí el autor cita distintos trabajos relativos a la relación entre agencias estatales brasileñas y entidades privadas bajo este paradigma. En tal sentido menciona documentos de Luciano Martins, E. Diniz y R. Boschi y de S. Abranches, entre otros.
} 
operaciones y hasta revertir el sentido de toda la actividad emprendida por la ETN. Este es un rasgo de imprevisibilidad que pone a la empresa en una situación de inestabilidad estructural a la vista de sus propios cuadros ${ }^{42}$. Pero, simultáneamente, garantiza la supervivencia en la medida que la pérdida de determinadas funciones pueda ser exitosamente sobrellevada. Abreviando, a esta característica la llamaría "multipolaridad intelectiva". Así, por ejemplo, los criterios de racionalidad aplicados en la logística, el transporte o las telecomunicaciones no pueden ser simplemente "dictados" de manera irreversible por quienes diseñan desde una matriz el camino crítico mediante la incorporación de insumos en distintas instancias y "estaciones" geográficas de manufacturación. Un cambio en el diseño y uso de determinados tipos de materias primas, insumos u operaciones usualmente constituyen incitaciones ineludibles para reformular funciones que a su vez atraviesan a la empresa de lado a lado.

Más aún: la misma ETN puede verse obligada a modificaciones estructurales o desaparecer a través de la venta de sus activos. Las modificaciones estructurales ocurren cuando los cambios contextuales alteran el peso original asignado a cada una de las áreas o sectores estratégicos $y$, en tal caso, la reformulación de la propiedad y el control de las operaciones responden a ese cambio. $Y$ en cambio la empresa desaparece cuando los cambios contextuales arrasan a todas y cada una de las áreas o sectores, esto es, cuando la empresa no puede cumplir los estándares de la multipolaridad: no es el pólipo que se presumía que era.

Semejante grado de plasticidad del cual parece depender la supervivencia de las ETN en la economía global, es imposible de ser imitado mediante creaciones o manipulaciones burocráticas, ya se trate de empresas binacionales 0 multinacionales subregionales puramente estatales, para-estatales o mixtas. Desde el mismo punto de partida corren en desventaja frente a las ETN, cualesquiera sean los planes de negocios fijados como metas políticas mediante reglamentaciones

\footnotetext{
42 "La habilidad que requiere una organización flexible es la capacidad para trabajar bien en equipos de corta vida, es decir, con otros a quienes no se tiene tiempo de conocer bien. Una vez que el equipo se disuelve y uno entra en un nuevo grupo, el problema reside en ponerse a trabajar lo más rápidamente posible con esos nuevos compañeros de trabajo. "Puedo trabajar con cualquiera" es la fórmula social de la capacidad potencial. No importa quién es la otra persona; en las empresas de cambios rápidos no tiene por qué importar. La habilidad personal reside en cooperar, con independencia de las circunstancias" (Richard Sennett": "La cultura del nuevo capitalismo", Editorial Anagrama, Barcelona, cuarta edición, septiembre 2013, páginas 110 y 111).
} 

Año XXIII, N³6/Junio 2017, ISSN 2468-9912. DNDA: 5318259 en línea

Marcelo Halperin

Las empresas transnacionales en el escenario latinoamericano del capitalismo tardío

Págs. 1 -43

\section{intergubernamentales o a través de disposiciones de organismos comunitarios supra-nacionales.}

En consecuencia fue infundada la pretensión de contrarrestar el predominio de determinadas ETN en los mercados latinoamericanos apelando al diseño y la creación de otras empresas multinacionales a título de un proyecto político compartido por dos o más Estados. Así, al momento de concretar esa formalización ya debe afrontarse una desventaja operativa difícilmente superable respecto de las ETN con las cuales dichas empresas multinacionales deberían competir. Semejante desventaja deriva del manejo de este primer resorte del desempeño internacional: la multipolaridad intelectiva. En otros términos: para sobrevivir las ETN tienden a fragmentarse o bien a ensamblarse con otras ETN o bien con organismos públicos nacionales sin atender a sus previsiones o metas fundacionales. Los desafíos o crisis inducidas en las organizaciones empresariales para facilitar el procesamiento interno de los conocimientos se han transformado en desafíos o crisis existenciales: la adquisición, creación, acumulación y explotación del conocimiento van tornándose incompatibles con las metas y estrategias dadas y concentradas.

Seguramente la desventaja de los proyectos subregionales no era tan ostensible cuando en la década de los setenta las iniciativas afloraron en América Latina con gran entusiasmo. Parecía entonces que la clave del desempeño empresarial radicaba en la dotación de capital y tecnología aplicada a la producción básicamente localizada en un asentamiento principal. Sin embargo, ni siquiera en esa época las iniciativas intergubernamentales pudieron ensayar los primeros pasos hacia una competencia comercial con las ETN.

Estos rasgos de multipolaridad intelectiva que hoy día definen a las ETN resguardando su supervivencia en la economía global, ofrecen algunas manifestaciones llamativas:

(i) Las necesidades de supervivencia tienden a borrar un límite que la teoría jurídica consideraba infranqueable: lo público y lo privado ahora se entrecruzan. Es decir que aparecen engendros asociativos, societarios o contractuales que pueden conducir a resultados inmanejables al determinar los órdenes de competencia estatal y las responsabilidades privadas. 
Revista Aportes para la Integración Latinoamericana Año XXIII, N³6/Junio 2017, ISSN 2468-9912. DNDA: 5318259 en línea

Marcelo Halperin

Las empresas transnacionales en el escenario latinoamericano del capitalismo tardío

Págs. 1-43

(ii) Las necesidades de supervivencia tienden a borrar otro límite que la teoría jurídica delineaba con cierta precisión: el que distinguía los derechos de propiedad industrial en cabeza de los titulares registrales frente a los derechos colectivos o comunitarios erigidos como contrapeso de la exclusividad garantizada por el registro. Las innovaciones tecnológicas destinadas a reproducir el capital, al difundirse mediante vías no convencionales le van escapando a las garras registrales y así pasan en la práctica al dominio público. Este "derrame" de potencial capital reproductivo puede avizorarse:

-A través de la creciente "acumulación de conocimiento tácito" según la expresión utilizada por M. Polanyi, ${ }^{43}$ en el sentido que la vorágine de innovaciones tecnológicas genera un acervo de informaciones y de modelos o patrones interpretativos no asimilables por la capacidad de verbalización humana pero que resultan indispensables para completar los circuitos de producción y aplicación del conocimiento;

-Como consecuencia de estar pasando permanentemente al dominio público, a través de las redes audiovisuales, un cúmulo de novedades que los mismos usuarios van remodelando, adaptando y reconfigurando a sus necesidades; y

-Por la interacción -todavía incipiente- en la que intervienen máquinas dotadas de capacidad para el aprendizaje y que vuelcan -también al dominio público- los desarrollos de su inteligencia artificial.

En síntesis, resultan aleccionadores los hallazgos de J. Habermas mencionados más arriba porque al cabo de algunos años aquellas "compensaciones" debidas a los efectos adversos de la globalización se han vuelto tan onerosas que comprometen el proceso de acumulación reproductiva o la "apropiación del fruto" (recurriendo al léxico de R. Prebisch $\left.{ }^{44}\right)$.

\section{CONCLUSIONES Y CONJETURAS}

\footnotetext{
${ }^{43}$ José Tavares de Araujo Jr.: "Progreso técnico y política industrial: el caso de paneles de LCD" (Breves CINDES 96, noviembre 2016, en portugués). Las ideas de Michael Polanyi acerca de la extraordinaria relevancia social del "conocimiento tácito" ("The Tacit Dimension", The University Chicago Press Books, 1966) han sido aplicadas fructíferamente a los procesos organizacionales por I. Nonaka e H. Takeuchi en un trabajo citado más arriba.

${ }^{44}$ Véase Raúl Prebisch: "La periferia latinoamericana en la crisis global del capitalismo", Cuaderno número 3 de la Fundación Raúl Prebisch, Buenos Aires, editorial Tesis, página 39.
} 
Revista Aportes para la Integración Latinoamericana Año XXIII, N³6/Junio 2017, ISSN 2468-9912. DNDA: 5318259 en línea

Marcelo Halperin

Las empresas transnacionales en el escenario latinoamericano del capitalismo tardío

Págs. $1-43$

Los rasgos que en una primera aproximación aparecen como ejemplos de plasticidad estatal y empresarial en un diálogo de mutua conveniencia, estarían significando potencialmente lo contrario: serían señales de incipiente rigidez para todo el sistema económico internacional. En lugar de la virtuosa fluidez tanto política como corporativa, estaríamos ante un "vicioso" derrame de factores y recursos. Los Estados nacionales, para subsistir como fuentes regulatorias y preservar a sus poblaciones frente a los efectos adversos de la globalización, deben hacer crecientes concesiones y aún interactuar con ETN a las que, por las propias características de estas últimas, no pueden controlar. Por lo tanto tienden a quedar entrampados por una progresiva erosión de sus competencias, Simultáneamente las ETN ven como se les escurre el fruto del capital reproductivo al mismo tiempo que lo van gestando. $Y$ en este punto merece destacarse la justificación del escurrimiento: los beneficiarios inmediatos de recursos tecnológicos volcados al uso y al consumo masivo sin contraprestación visible, pueden legitimar su apropiación bajo el manto florido de una supuesta igualación de derechos para el acceso a las fuentes del bienestar. Así va erosionándose tanto el soporte político (Estados nacionales que no pueden hacerse cargo por sí solos de la supervivencia de sus residentes) como el soporte económico (ETN con crecientes dificultades para la reproducción del capital). La danza continúa, pero al ritmo de una música que dentro de algún tiempo podría llegar a ser inaudible para los propios danzarines.

Ante los procesos de progresiva fragmentación y vaciamiento de las capacidades autonómicas tanto de los Estados nacionales como de las ETN y en especial a propósito de sus vinculaciones recíprocas, quizás puedan justificarse algunas conclusiones predictivas. Pero ante todo propongo desechar las hipótesis que recorren los claustros, según las cuales aquella puja entre los Estados nacionales y las ETN tendería a resolverse con la supremacía de una de las entidades sobre la otra.

De un lado, los proyectos para instalar empresas multinacionales subregionales e iniciativas afines ideadas como resortes productivos de una política de integración o complementación enfrentada a las agresivas ETN, han reflejado una y otra vez la pretensión de doblegar a estas últimas. Los pobres resultados obtenidos hablan por sí solos. 

Año XXIII, N³6/Junio 2017, ISSN 2468-9912. DNDA: 5318259 en línea

Marcelo Halperin

Las empresas transnacionales en el escenario latinoamericano del capitalismo tardío

Págs. 1 -43

Del otro lado, parece tener hoy día mayor audiencia -dentro y fuera de las academias- el discurso tecnocrático que aboga por la racionalidad de una inserción en las cadenas globales de valor o fábricas mundiales. Esta perspectiva desprecia la viabilidad histórica de los Estados nacionales por considerar que obstruyen anacrónicamente la edificación del orden transnacional, el cual, liberado de sus restricciones, habría de garantizar un flujo irrestricto de factores y recursos. Pero esta hipótesis tampoco seduce demasiado al comprobarse la endeblez de los mecanismos de propiedad y control de las ETN frente a las turbulencias cotidianas de una economía global funcionando al ritmo vertiginoso impreso por la necesidad de reproducir el capital antes de ser difuminado como bien público. En el fragor de estas batallas, las ETN demuestran que sólo subsisten al precio de continuas fragmentaciones y reconfiguraciones.

Al modo de dos pugilistas en el ring agotados por el esfuerzo, los Estados nacionales y las ETN se sostienen recurriendo al abrazo recíproco. En síntesis, tanto los Estados nacionales como las ETN van perdiendo jirones mientras perseveran en una lucha desgastante. Tal proclividad a la fractura organizacional parece ir reduciendo a unos y otros protagonistas a la condición transitoria de "agregados". Esto es, los componentes de entidades complejas pueden adquirir entidad propia (o perderla) en el curso de acción con sus distintos entornos. $Y$ el desempeño ha de reputarse como exitoso cuando estas entidades desgajadas de sus núcleos de pertenencia original, comienzan a exhibir una capacidad de "recomposición" pasando a ser los núcleos emergentes de otras nuevas organizaciones complejas.

En consecuencia, así como parecen inconsistentes las hipótesis sobre un ganador y un perdedor, también debería descartarse la hipótesis de la disolución sin retorno. Si la clave de subsistencia de la especie humana reposa no en sus constructos sino en las articulaciones o redes que los conectan, hacen y deshacen, entonces habría que imaginar esta misma figura, por lo menos para la transición entre el desmembramiento del capitalismo tardío (donde las ETN y los Estados nacionales todavía coexisten lastimosamente como entidades inseparables) y la consolidación de un sistema que lo sustituya. Con respecto a los Estados nacionales, parece coherente inferir la tendencia a su progresiva reducción geopolítica, siguiendo un sentido estrictamente contrario al ensueño romántico que ha venido animando las iniciativas de integración 
Revista Aportes para la Integración Latinoamericana Año XXIII, N³6/Junio 2017, ISSN 2468-9912. DNDA: 5318259 en línea

Marcelo Halperin

Las empresas transnacionales en el escenario latinoamericano del capitalismo tardío

Págs. 1-43

\section{económica y política, según el imaginario que durante siglos anudó la concentración del poder con el triunfo de la racionalidad.}

Las desarticulaciones estructurales tanto en los Estados nacionales como en las ETN estarían ofreciendo un caldo de cultivo donde podrían desarrollarse nuevas condiciones para la convivencia humana. Todavía sin suficientes elementos como para entrever la caracterización de algún otro modo de producción en ciernes, hay señales notorias sobre la difusión en el inconsciente colectivo de una necesidad que no puede obtener respuesta dentro de las condiciones actuales: la necesidad de reducir la incertidumbre.

Los motivos de esta presunción sobre la necesidad de reducir la incertidumbre son susceptibles de ser agrupados en dos categorías descriptivas:

(i) Un síntoma de alerta político, económico y social golpeando las expectativas de previsibilidad y confiabilidad para sostener la vida cotidiana. Este síntoma debe asociarse al debilitamiento de los procesos de socialización y educación que habían venido operando secularmente inhibiendo los desbordes de conducta individual y colectiva. En este panorama se aprecia como la difusión social de las innovaciones tecnológicas ahora incluye la difusión de recursos y dispositivos aptos para producir daños masivos y hasta catástrofes humanitarias.

(ii) Otro síntoma de alerta político, económico y social que si bien todavía no golpea las expectativas de previsibilidad y confiabilidad en la vida cotidiana, tiende a difundirse particularmente dentro de las generaciones más jóvenes: la creencia sobre un progresivo aumento de la vulnerabilidad del planeta como hábitat, en parte por la explotación de los recursos no renovables y la destrucción de la biodiversidad; y en parte por el conocimiento sobre distintos tipos de eventos cósmicos de probable ocurrencia. ${ }^{45}$

45 El 13 de octubre de 2016 el Presidente Obama emitió una "Executive Order" titulada "Coordinating Efforts to Prepare the Nation for Space Weather Events". En ella dispuso los objetivos y consiguientes cronogramas de trabajo que distintos departamentos y organismos del Estado debían cumplir en prevención de hipotéticos eventos climáticos espaciales de carácter extremo. Un antecedente cercano tenido en cuenta, fue sin duda el de la sucesión de eyecciones de masa coronal en el Sol que en julio de 2012 generó una nube de plasma magnetizado que a su vez atravesó la órbita terrestre en un punto que el planeta esquivó azarosamente por sólo nueve días de diferencia. La magnitud de este tipo de amenaza está ilustrada por las expresiones que utiliza el documento citado en su Sección 1: "...Space weather events, in the form of solar flares, 
Revista Aportes para la Integración Latinoamericana Año XXIII, N³6/Junio 2017, ISSN 2468-9912. DNDA: 5318259 en línea

Marcelo Halperin

Las empresas transnacionales en el escenario latinoamericano del capitalismo tardío

Págs. 1-43

¿Cómo está delineándose la defensa de los cuerpos políticos (Estados nacionales), económicos (ETN) y sociales (círculos intelectuales y científicos) frente a semejantes síntomas? Por distintas vías se observa que tienden a propagarse institucionalmente y de manera simultánea y combinada los recursos ya instalados por la lógica digital: los recursos de tipo conectivo y los recursos de tipo disruptivo. Propongo llamar "recursos conectivos" a los que están permitiendo a los humanos una vinculación a través de redes cuya extensión, diversificación e intensidad es inédita. $Y$ propongo llamar "recursos disruptivos" a los que están permitiendo a los humanos una interrupción de esa misma conectividad, así como el mantenimiento autónomo y descentralizado de las fuentes de energía y del conocimiento acumulado mientras las redes son recompuestas.

Los recursos conectivos merecen mayor atención bibliográfica, pero para reducir la incertidumbre resulta indispensable completar la oferta de la lógica digital incorporando, con el mismo nivel de criticidad, a los recursos disruptivos. En consecuencia, algunos de los principales problemas que están pendientes de resolución política, económica y social, son los relativos a cómo y cuándo han de dispararse los "interruptores"; cómo se preservarán las fuentes de energía y el acervo de conocimientos en ausencia de conectividad; y cómo se repararán o recompondrán las redes.

Este cuadro de situación hace suponer que la convivencia humana se debería reorganizar institucionalmente a través de agregados políticos complejos como son los Estados nacionales pero funcionando en calidad de nodos (con algún parecido a las ciudades-

solar energetic particles, and geomagnetic disturbances, occur regularly, some with measurable effects on critical infrastructure systems and technologies, such as the Global Positioning System (GPS), satellite operations and communication, aviation, and the electrical power grid. Extreme space weather events -those that could significantly degrade critical infrastructure-could disable large portions of the electrical power grid, resulting in cascading failures that would affect key services such as water supply, healthcare, and transportation...".

A fin de reducir las pérdidas humanas y materiales, a continuación el texto indica cuál es el tenor del compromiso a ser asumido por el Gobierno Federal: "The Federal Government must have (1) the capability to predict and detect a space weather event; (2) the plans and programs necessary to alert the public and private sectors to enable mitigating actions for an impending space weather event; (3) the protection and mitigation plans, protocols, and standards required to reduce risks to critical infrastructure prior to and during a credible threat; and (4) the ability to respond to and recover from the effects of space weather Executive departments and agencies (agencies) must coordinate their efforts to prepare for the effects of space weather events". 
Revista Aportes para la Integración Latinoamericana Año XXIII, N³6/Junio 2017, ISSN 2468-9912. DNDA: 5318259 en línea

Marcelo Halperin

Las empresas transnacionales en el escenario latinoamericano del capitalismo tardío

Págs. $1-43$

Estado de la Antigua Grecia), conectados en red mediante todos los tipos de flujos interactivos disponibles y maximizando la viabilidad o supervivencia de cada nodo a través de la adquisición de capacidades para la supervivencia en condiciones de aislamiento (sin red).

La actividad económica tendría entonces que contribuir a la reproducción de las condiciones de supervivencia propias de cada nodo y, en tal sentido, habría de articularse con el resto del mundo en una labor arácnida de tejido y entretejido de las redes. Así quedaría delineado el campo de juego para la renovación de las porfías por el dominio político y económico, es decir, los nuevos términos del inagotable devaneo que anuda centros y periferias. En estas pujas parecerían reducirse las perspectivas de supervivencia de muchos Estados de países en desarrollo que, debido a su dependencia neocolonial, han alcanzado una expansión fiscal (urgidos por las agudas demandas sociales) que coexiste con la escasa dotación de recursos conectivos y especialmente disruptivos (Estados no-inteligentes o "bobos").

Aquí cabe advertir que los citados mecanismos de defensa política, económica y social para la configuración de un sistema donde los recursos conectivos y disruptivos puedan ser empleados simultánea o alternativamente, conducirán a una metamorfosis estructural de sus propios protagonistas, debido a que precisamente la incertidumbre es un efecto adverso pero insoslayable de la economía global, esto es, el resultado histórico de la misma interacción e interdependencia de los Estados nacionales con las ETN.

Si a los ojos del lector estas últimas divagaciones no parecen tan bizarras, es porque están reflejando una simbolización relativamente familiar y por ende asimilable sobre la base de las sorprendentes experiencias que nos van galvanizando cada día.

\section{BiblografíA}

BANCO INTERAMERICANO DE DESARROLLO (2014): "Fábricas sincronizadas. América Latina y el Caribe en la Era de las Cadenas Globales de Valor", coordinado por Juan Blyde.

CEPAL (1992): "Panorama reciente de los procesos de integración en América Latina y el Caribe", documento fechado el 15 de septiembre de 1992, catalogado LC/R1189.

(2014): "Integración Regional. Hacia una estrategia de cadenas de valor inclusivas", documento. 
Conferencia de las Naciones Unidas sobre Comercio y Desarrollo (UNCTAD) (1979): "Regímenes jurídicos para la creación de empresas multinacionales entre países en desarrollo establecidos por agrupaciones de integración y cooperación económica", Informe de la Secretaría conforme un programa de trabajo de la Comisión de Cooperación Económica entre Países en Desarrollo (fechado el 7 de mayo de 1979 y catalogado $\mathrm{TD} / \mathrm{B} / \mathrm{C} .7 / 30)$.

da Motta Veiga, Pedro (2011): "Los subsidios chinos absueltos", diario O Estado de S. Paulo, sección Economía, 16 de mayo de 2011.

Fernández, Gustavo (1972): "El régimen de las empresas multinacionales en el Grupo Andino", en revista Derecho de la Integración, INTAL, octubre de 1972, número 11.

Habermas, Jürgen. (1999): Problemas de legitimación en el capitalismo tardío, Amorrortu editores y Ediciones Cátedra S.A., Madrid.

Halperin, Marcelo (2010): "Las relaciones económicas internacionales y los países en desarrollo: el recurso a una racionalidad acotada", en revista Aportes para la Integración Latinoamericana, número 22, junio 2010.

(2015): "Propuestas para una sociología del conocimiento de la integración económica", en Mellado, Noemí -Editora-. Estrategias de inserción internacional e integración latinoamericana en el siglo XXI, Lerner ed., Córdoba, Argentina.

(2016): "Consecuencias del despoblamiento rural y la desorganización social en América Latina”, en Mellado, Noemí -Editora-. Latinoamérica: inserción global e integración regional, Lerner ed., Córdoba, Argentina.

Kosacoff, Bernardo y Porta, Fernando (1998): “Apertura y Estrategia de las Empresas Transnacionales en la Industria Argentina" en: B. Kosacoff: Estrategias empresariales en tiempos de cambio. El desempeño industrial frente a nuevas incertidumbres, Bernal, Universidad Nacional de Quilmes/CEPAL.

Marx, Karl (1973): El Capital, Libro primero, Editorial Cartago, Buenos Aires.

Naville, Pierre (1963): "El progreso técnico, la evolución del trabajo y la organización de la empresa", en Georges Friedmann y Pierre Naville: Tratado de Sociología del Trabajo, volumen I, Fondo de Cultura Económica, México.

Nonaka, Ikujiro y Takeuchi, Hirotaka (1999): "La organización creadora de conocimiento", Oxford University Press, editado en México.

Oszlak, Oscar (1980): Políticas públicas y regímenes políticos; reflexiones a partir de algunas experiencias latinoamericanas. Estudios CEDES, volumen 3, número 2.

Peña, Félix (1973): "Empresas binacionales y multinacionales latinoamericanas: ideas en torno a algunos de sus aspectos jurídicos", en: revista Derecho de la Integración número 13, Instituto para la Integración de América Latina, Banco Interamericano de Desarrollo, julio 1973. 
Prebisch, Raúl (1989): "La periferia latinoamericana en la crisis global del capitalismo", Cuaderno número 3 de la Fundación Raúl Prebisch, Buenos Aires, Editorial Tesis.

Sabanogullari, Levent (2015): "Los méritos y limitaciones de las cláusulas de excepción en la práctica contemporánea de los tratados de inversión", en: boletín "Investment Treaty News" del Instituto Internacional de Derecho Sustentable" número 2, tomo 6, mayo 2015.

Sennett, Richard (2013): La cultura del nuevo capitalismo, Editorial Anagrama, Barcelona, cuarta edición, septiembre 2013.

Serva, Mauricio (1992): "El paradigma de complejidad y el análisis organizacional", Revista de Administración de Empresas de la Fundación Getulio Vargas, volumen 32 número 2, abril-junio 1992, en portugués).

Taleb, Nassim Nicholas (2014): "El cisne negro, El impacto de lo altamente improbable", editorial Paidos, Barcelona, España.

Tavares de Araujo Jr., José (2016): "Progreso técnico y política industrial: el caso de paneles de LCD", Breves CINDES 96, noviembre 2016, en portugués.

(2017): "Anatomía de protección antidumping en Brasil", Textos CINDES número 45, marzo de 2017, Río de Janeiro, Brasil, en portugués.

Trajtenberg, Raúl (1999): "El concepto de empresa transnacional", Universidad de la República, Facultad de Ciencias Sociales, Departamento de Economía, documento de trabajo número 10/99, agosto 1999.

Vallat, Bernard (2008): "Considerations relevant to private standards in the fields of animal health, food safety and animal welfare" editado por la OMC el 25 de febrero de 2008 e individualizado como G/SPS/GEN/822.

Zhuang, Wei (2016): "Hacia un acuerdo comercial para regular los incentivos a las energías renovables", en revista Puentes, volumen 17 número 6, septiembre 2016.

HalPerin Marcelo: Abogado, Universidad Nacional de Buenos Aires. Egresado de la Escuela de Sociología. Doctor en Derecho y Ciencias Sociales por la Universidad Nacional de Córdoba, Argentina. Consultor de organismos internacionales de integración y cooperación económica. Investigador y docente del Instituto de Integración Latinoamericana de la Universidad Nacional de La Plata. 